\title{
D-cycloserine augmentation in behavioral therapy for obsessive-compulsive disorder: a meta-analysis
}

This article was published in the following Dove Press journal:

Drug Design, Development and Therapy

21 April 2015

Number of times this article has been viewed

Jing Xia'

Yanqiu Du

Jiyang Han' $^{\prime}$

Guo Liu'

Xumei Wang'

'Department of Psychiatry, Shengjing Hospital of China Medical University, Heping District Shenyang, Liaoning, People's Republic of

China; ${ }^{2}$ Department of Medicine, Shenyang Ninth People's Hospital,

Tiexi District, Shenyang, Liaoning,

People's Republic of China
Correspondence: Xumei Wang Department of Psychiatry, Shengjing Hospital of China Medical University, Number 36 Sanhao Street, Heping District Shenyang, Liaoning, I 1 0004, People's Republic of China Tel +8624966 I56 6I I I Email xumeiwang@।63.com
Objective: To evaluate the overall effect of D-cycloserine (DCS) augmentation on exposure and response prevention (ERP) therapy for obsessive-compulsive disorder (OCD).

Methods: Clinical studies on the effect of DCS augmentation on ERP therapy for OCD compared to placebo were included for meta analysis. The primary outcome was the Yale-Brown Obsessive-Compulsive Scale (Y-BOCS). Meta-analyses were performed with a random-effect model or a fixed-effect model using the Cochrane Review Manager (RevMan, version 5.2) to calculate the odds ratio and the mean difference, with their corresponding $95 \%$ confidence intervals.

Results: A total of six studies was included in the current meta-analyses, and their data were extracted. Among them, four were for analyses of DCS and Y-BOCS at midtreatment, six for analysis at posttreatment, and four at 3-month follow-up. Besides, three of the six eligible studies were included in the meta-analysis of the DCS and Clinical Global Impression - Severity Scale at posttreatment, and three in the meta-analysis of DCS and proportions of treatment responders and of subjects attaining clinical remission status criteria at posttreatment. Our meta-analyses do not reveal a significant effect of DCS augmentation in ERP therapy for OCD patients, except when measured at midtreatment. Compared to the placebo group, DCS augmentation did show a trend toward significantly lower/decreased Y-BOCS; when measured at posttreatment and in the subpopulation of DCS taken before some of the ERP sessions, DCS augmentation showed a trend toward significantly lower/decreased Y-BOCS.

Conclusion: Our result suggested that with the careful optimization of DCS-augmented ERP therapy by fine-tuning timing and dosing of DCS administration and number and frequency of ERP sessions, DCS may enhance the efficacy of ERP therapy in reducing the symptomatic severity of OCD patients, especially at early stage of the treatment; therefore, DCS augmentation could possibly reduce treatment cost, reduce treatment drop and refusal rate, and help to improve access to the limited number of experienced therapists.

Keywords: D-cycloserine, obsessive-compulsive disorder, exposure and response prevention, Yale-Brown Obsessive-Compulsive Scale (Y-BOCS), Clinical Global Impression - Severity Scale (CGI-S)

\section{Introduction}

Obsessive-compulsive disorder (OCD) is a chronic, severe, and often disabling disorder featuring either obsession or compulsive rituals, or most commonly, both. ${ }^{1}$ This disorder has a lifetime prevalence of $2 \%-3 \%$ in the general population, ${ }^{2}$ which usually arises in late adolescence or early adulthood, though the onset in childhood or late adulthood could also happen; the clinical presentation of OCD in children and adults is similar. ${ }^{1,3}$

Exposure and response prevention (ERP) is currently considered the gold standard psychological intervention for OCD. ERP works by facilitating fear extinction 
by exposing OCD patients to systematic and prolonged anxiety-provoking stimuli and at the same time preventing fear-reducing physical or mental actions, such as rituals or avoidance. ${ }^{4}$ Although ERP therapy has proven to be efficacious for treating OCD, it does not help all OCD patients, even those who benefit from the therapy, as they often still remain symptomatic after completing the ERP treatment. ${ }^{5}$ Alternative treatments, such as serotonergic medications, only have modest efficacy and usually have adverse side effects. ${ }^{6,7}$ To improve the efficacy of ERP therapy, various augmentation strategies have been proposed and tested; however, issues such as drug side effects and limited access to ERP practitioners prevent the successful implementation of these strategies. ${ }^{8}$ Evidence in recent years suggests that the $N$-methyl-D-aspartate (NMDA) system plays a critical role in the neural process underlying learned associations and fear extinction ${ }^{9}$ and that the antituberculosis medicine D-cycloserine (DCS), a partial NMDA agonist, enhances extinction of learned fear. ${ }^{10,11}$ Studies further reported that DCS has improved exposure therapy outcomes in adult studies of acrophobia, ${ }^{12}$ social phobia, ${ }^{13,14}$ and panic disorder. ${ }^{15}$

However, trials on DCS-augmented ERP in OCD subjects produced somewhat mixed and inconsistent results. Wilhelm et al reported a significant reduction of OCD severity rate ( $d=1.17$ ) by midtreatment (session 5 ) for the DCS group versus the placebo group; however, such significant difference was not present at posttreatment (right after session 10) nor 1-month follow-up. ${ }^{16}$ Wilhelm et al found further significant improvement in depressive symptoms in the DCS group versus the placebo group at posttreatment, but not at midtreatment nor at 1-month follow-up. ${ }^{16}$

Kushner et al reported a significantly greater decrease in obsession-related distress with patients in the DCS group, compared with the placebo group after four sessions, although the placebo group did catch up in the later sessions, and he concluded that DCS decreases the number of exposure sessions required to reach clinical milestones. ${ }^{17}$ Farrell et al further reported that when compared to ERP + placebo, DCSaugmented ERP led to significantly greater improvement in OCD severity from posttreatment to 1-month follow-up in patients with difficult-to-treat OCD. ${ }^{18}$

On the other hand, two studies by Storch et $\mathrm{a}^{8,19}$ and one study by Mataix-Cols et a ${ }^{20}$ found no significant beneficial effect of DCS administration over placebo, although one of the studies by Storch et al reported that compared with the placebo control, DCS augmentation led to small to moderate treatment effects on various primary outcomes at posttreatment. ${ }^{19}$
Although there have been two meta-analysis articles including studies on DCS-augmented ERP on OCD patients, ${ }^{10,21}$ both articles included trials on subjects with acrophobia, social anxiety disorder, panic disorder, or OCD without subpopulation analyses. Further, neither article addresses the effect of DCS at a different time point of the ERP therapy, ie, midtreatment, posttreatment, and follow-up. The main aim of the current study was to perform meta-analyses of all available studies comparing the effects of DCS-augmented ERP therapy and placebo-augmented therapy on OCD subjects to determine whether the DCS does enhance ERP therapy in OCD subjects compared to a placebo at a different time point of the ERP therapy. This could help researchers to choose the future directions of the studies on this topic.

\section{Methods}

\section{Search strategy}

The PubMed/MedLine and Web of Science databases (Web of Knowledge) were searched up to December 31, 2013 to identify all published studies relating to the effect of DCS-augmented ERP therapy on OCD patients compared to placebo-augmented ERP therapy. The following search terms were used: "obsessive compulsive", "OCD", "D-cycloserine", "seromycin", and "DCS".

\section{Inclusion and exclusion criteria}

Published studies (criterion 1) reporting the effect of DCSaugmented ERP therapy on OCD patients compared to placebo-augmented ERP therapy (criterion 2) on all ethnic groups were all potentially eligible for inclusion in the current meta-analyses. Reviews, meeting abstracts, and case-only studies were excluded.

Two authors (JX and YD) independently selected studies potentially eligible for the current meta-analyses by reviewing the titles and abstracts identified through the search, followed by examining independently the full text of all of the studies considered potentially eligible. Any disagreement regarding whether a study should be included was resolved by discussion that was participated in by all contributing authors until a consensus was reached by all.

\section{Outcome measures}

The primary outcome measure was the Yale-Brown ObsessiveCompulsive Scale (Y-BOCS) of the OCD subjects at midtreatment, posttreatment, and 3-month follow-up, as well as the decrease of Y-BOCS values at midtreatment, posttreatment, and 3-month follow-up, compared to pretreatment. Y-BOCS has sound psychometric properties and is considered to 
be the gold standard measure of obsessive-compulsive symptoms. ${ }^{22,23}$ We also used the Clinical Global Impression Severity Scale (CGI-S) of the OCD subjects at posttreatment and its decrease compared to pretreatment as a supplementary primary outcome measure. CGI-S is a clinical rating of the severity of OCD symptoms, which is widely used and treatment sensitive. ${ }^{24}$ Since there were not enough studies, we did not perform meta-analysis on the CGI-S value and mean change at midtreatment and 3-month follow-up.

The secondary outcome measures were the proportion of the treatment responders and the proportion of OCD subjects attaining clinical remission criteria status (assessed by the original study criteria) at posttreatment. Since there were not enough studies, we did not perform meta-analysis on the proportion of treatment responders and proportion of the OCD subjects attaining clinical remission criteria status at midtreatment and 3-month follow-up.

\section{Data extraction}

Two authors (JX and YD) independently extracted data, and any disagreement between these two was resolved by discussion. From each study, the following information was extracted: the first author; year of publication; methodology details, including study design, sample size for both the DCS group and placebo group; diagnostic tools for determining OCD status, treatment responder status, and subjects attaining clinical remission criteria status whenever the information was available; sample characteristics, including sex ratio, mean age, ethnic background; primary outcome measures including Y-BOCS of subjects in DCS and placebo groups at pretreatment, midtreatment, posttreatment, and 3-month follow-up; and CGI-S value of subjects in both groups at posttreatment whenever the information was available. The secondary outcome measures included the numbers of treatment responders and of subjects attaining clinical remission status criteria in both groups whenever the information was available. Decrease of Y-BOCS value of subjects in both groups at pretreatment, midtreatment, posttreatment, and 3-month follow-up compared to pretreatment and decrease of CGI-S value of subjects in both groups at posttreatment compared to pretreatment were deduced.

\section{Quality of the studies}

The quality of each included study was evaluated by two methods. Each study's adequacy in four key areas (methodological, genetic, clinical, and statistical) was evaluated first. Then, all the studies were screened with the NewcastleOttawa Scale. ${ }^{25}$

\section{Statistical analysis}

All statistical analysis was performed using the Cochrane Review Manager (RevMan, version 5.2; The Cochrane Collaboration, London, UK). Our primary outcome measures (Y-BOCS value, CGI-S value, and decreases in Y-BOCS and CGI-S) were analyzed using mean difference (MD), while our secondary outcome measures (proportion of treatment responders and proportion of subjects attaining clinical remission status criteria) were analyzed using pooled odds ratio (OR). Pooled OR with its corresponding 95\% confidence interval (CI) and the MD with its corresponding 95\% CI were first calculated with a random-effect model, because heterogeneity among the studies was assumed and a randomeffect model assumes a genuine diversity in the results of the included studies and incorporates a between-studies variance into the calculation accordingly. ${ }^{26}$ The statistical significance of the pooled OR and MD was evaluated using the $Z$ test. Between-studies heterogeneity was assessed using the chisquare $\left(\chi^{2}\right)$ test based on the Cochran $\mathrm{Q}$ statistic. ${ }^{27}$

Further $I^{2}$ index was used to quantify heterogeneity; wherein, the $I^{2}$ value around $25 \%, 50 \%$, and $75 \%$ represented low, moderate, and large heterogeneity, respectively. ${ }^{28}$ When no heterogeneity was found using the random-effect model, data were further analyzed using a fixed-effect model. A $P$-value of $<0.05$ was considered to be statistically significant except for the Q statistics, wherein, a $P$-value of $<0.10$ was considered to be statistically significant.

Subpopulation analyses were also performed according to the timing of the DCS administration, whenever possible. Studies included in the meta-analyses were separated into the groups of DCS taken before each of the ERP sessions, DCS taken before some of the ERP sessions, and DCS taken after each of the ERP sessions.

Further, to examine the effect of excluding specific studies, a sensitivity analysis was also performed using a stepwise process in the meta-analyses; wherein, a single study included in the meta-analyses was excluded each time to reflect the influence of the data from said study on the MD and pooled OR. Finally, funnel plots were used to assess publication bias in the analysis.

\section{Results}

\section{Eligible studies and study characteristics}

Figure 1 describes the search process flow and results. From a total of 28 potentially eligible studies, 22 articles were excluded because they were: reviews: ${ }^{29-45}$ not relevant to the study question; ${ }^{46-48}$ analysis of a previous study included in the current meta-analyses $;{ }^{49}$ and letter to the editor. ${ }^{50}$ 


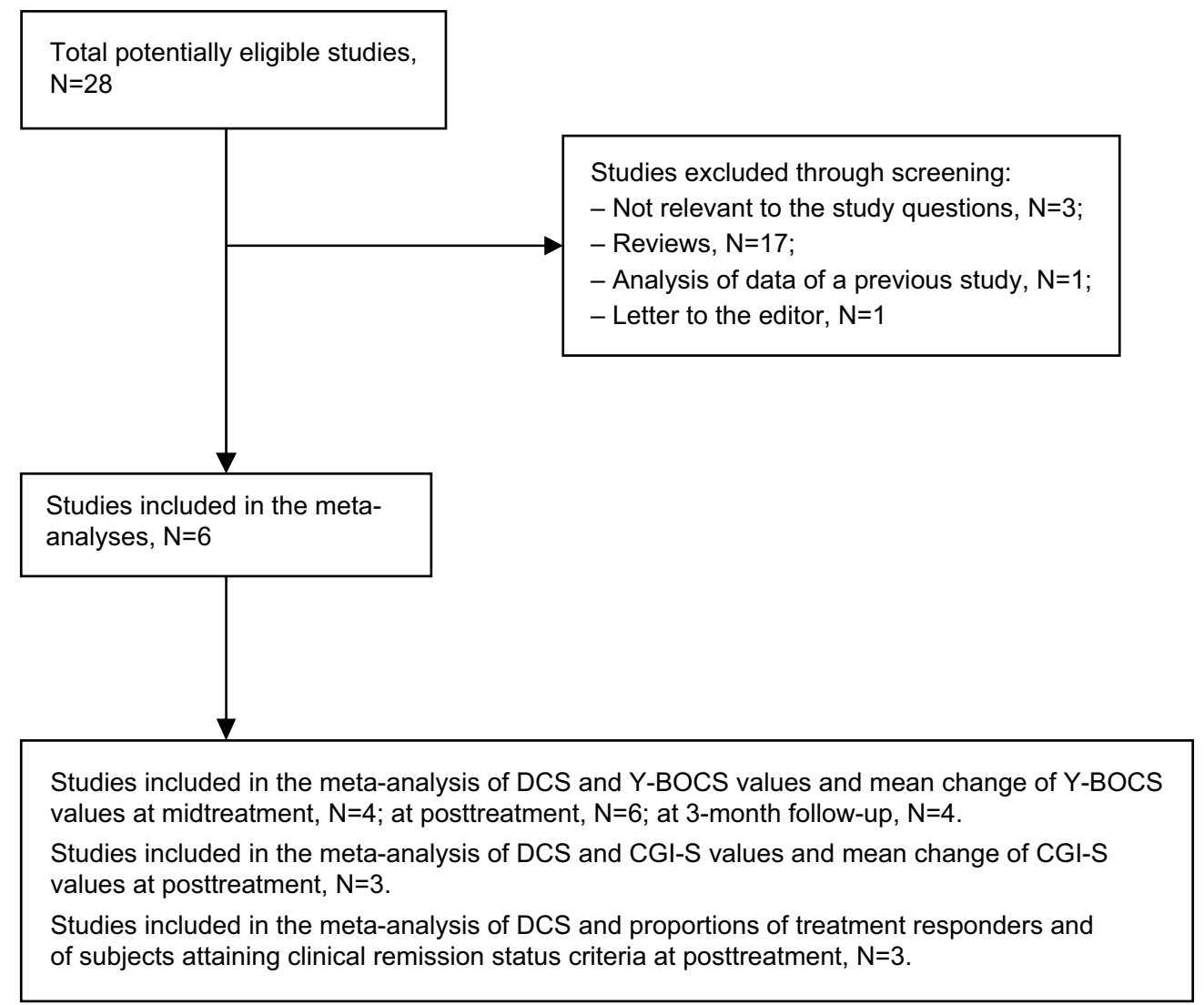

Figure I Flow diagram of publication selection process.

Abbreviations: DCS, D-cycloserine; Y-BOCS, Yale-Brown Obsessive Compulsive Scale; CGI-S, Clinical Global Improvement - Severity Scale.

A total of six studies ${ }^{8,16-20}$ was included in the current metaanalyses, and their data were extracted. Among them, four were included in the meta-analysis of DCS, Y-BOCS and the decrease of Y-BOCS at the midtreatment. ${ }^{16,17,19,20}$ Six were included in the meta-analysis of DCS, Y-BOCS, and the decrease of Y-BOCS at posttreatment, ${ }^{8,16-20}$ and four were included in the meta-analysis of DCS, Y-BOCS, and the decrease of Y-BOCS at 3-month follow-up. ${ }^{8,17,18,20}$ Three were included in the meta-analysis of DCS, CGI-S, and the decrease of CGI-S at posttreatment, ${ }^{8,18,19}$ and three were included in the meta-analysis of DCS and proportion of treatment responders, and these same three studies were also included in the meta-analysis of DCS and proportion of subjects attaining clinical remission status criteria at posttreatment. ${ }^{8,18,20}$

The characteristics of the six studies included in the current meta-analyses are described in Tables 1-7. Decreases of Y-BOCS value of subjects in both groups at pretreatment, midtreatment, posttreatment, and 3-month follow-up compared to pretreatment and decreases of CGI-S value of subjects in both groups at posttreatment compared to pretreatment, were deduced whenever possible. The pooled population included: 52 cases in the DCS group and 53 cases in the placebo group for the meta-analyses of DCS and Y-BOCS value and of DCS and decrease of Y-BOCS value at midtreatment (Table 2); 51 DCS cases and 51 placebo cases for the meta-analyses of DCS and Y-BOCS value and of DCS and decrease of Y-BOCS value at posttreatment (Table 3); 48 DCS cases and 44 placebo cases for the meta-analyses of DCS and Y-BOCS value and of DCS and decrease of Y-BOCS value at 3-month follow-up (Table 4); 36 DCS cases and 35 placebo cases for the meta-analyses of DCS and CGI-S value and of DCS and decrease of CGI-S value at posttreatment (Table 5); and 34 DCS cases and 34 placebo cases for the meta-analyses of DCS and proportion of treatment responder and of DCS and proportion of subjects attaining clinical remission status criteria at posttreatment (Tables 6 and 7, respectively).

\section{Meta-analyses of DCS and Y-BOCS at midtreatment}

Meta-analyses comparing the effects of DCS-augmented ERP therapy and placebo-augmented ERP therapy on the Y-BOCS value and decrease of Y-BOCS value of the OCD 
Table I Characteristics of studies included in the meta-analyses

\begin{tabular}{|c|c|c|c|c|c|c|c|}
\hline $\begin{array}{l}\text { First } \\
\text { author }\end{array}$ & $\begin{array}{l}\text { Population } \\
\text { ethnicity }\end{array}$ & $\begin{array}{l}\text { Total } \\
\text { sample } \\
\text { (N) }\end{array}$ & $\begin{array}{l}\text { Subjects receiving } \\
\text { DCS/subjects } \\
\text { receiving placebo }\end{array}$ & $\begin{array}{l}\text { Male/ } \\
\text { female }\end{array}$ & $\begin{array}{l}\text { Age } \\
(\text { mean } \pm S D)\end{array}$ & Subjects & Diagnostic tools \\
\hline $\begin{array}{l}\text { Kushner } \\
2007^{17}\end{array}$ & - & 25 & $14 / \mid 1$ & - & - & $\begin{array}{l}\text { Each subject with OCD } \\
\text { received ten doses of } \\
\text { I25 mg DCS or placebo } \\
\text { doses and took one } \\
\text { dose of study medication } \\
\sim 2 \text { hours before } \\
\text { each exposure/ritual } \\
\text { prevention. ERP therapy } \\
\text { session conducted twice } \\
\text { weekly }\end{array}$ & $\begin{array}{l}\text { OCD diagnosed by } \\
\text { Structured Clinical } \\
\text { Interview for DSM- } \\
\text { IV } \mathrm{V}^{52} \text { and a Y-BOCS } \\
\text { score } \geq 18^{53}\end{array}$ \\
\hline $\begin{array}{l}\text { Storch } \\
2007^{8}\end{array}$ & $\begin{array}{l}22 \text { Caucasian; } \\
\text { I African; } \\
\text { I Asian }\end{array}$ & 24 & $12 / 12$ & $12 / 12$ & $29.0 \pm 9.9$ & $\begin{array}{l}\text { Each subject with OCD } \\
\text { took DCS or placebo } \\
\text { ( } 250 \mathrm{mg}) 4 \text { hours before } \\
\text { each ERP therapy session. } \\
\text { Total I } 2 \text { weekly sessions }\end{array}$ & $\begin{array}{l}\text { Diagnosis of OCD } \\
\text { according to DSM- } \\
\text { IV-TR criteria and } \\
\text { then verified through } \\
\text { administration of the } \\
\text { ADIS for DSM-IV } 54 \\
\text { and Y-BOCS }\end{array}$ \\
\hline $\begin{array}{l}\text { Wilhelm } \\
2008^{16}\end{array}$ & - & 23 & $10 / 13$ & - & $\begin{array}{l}40.0 \pm 13.4 \text { for } \\
\text { DCS group; } \\
38.2 \pm 13.0 \text { for } \\
\text { placebo group }\end{array}$ & $\begin{array}{l}\text { Subjects with OCD. Each } \\
\text { took } 100 \mathrm{mg} \text { DCS or } \\
\text { placebo I hour before } \\
\text { each of the ten exposure- } \\
\text { based behavioral therapy } \\
\text { sessions (conducted } \\
\text { twice per week) }\end{array}$ & $\begin{array}{l}\text { DSM-IV diagnosis } \\
\text { of OCD }\end{array}$ \\
\hline $\begin{array}{l}\text { Storch } \\
2010^{19}\end{array}$ & $\begin{array}{l}\text { 97\% Caucasian; } \\
3 \% \text { Hispanic }\end{array}$ & 30 & $15 / 15$ & $19 / 11$ & $12.2 \pm 2.8$ & $\begin{array}{l}\text { Subject (child) with } \\
\text { OCD. Each took DCS } \\
\text { or placebo I hour } \\
\text { before each CBT session } \\
4-10 \text { ( } 25 \mathrm{mg} \text { for children } \\
\text { weighing between } \\
25-45 \mathrm{~kg} \text { and } 50 \mathrm{mg} \\
\text { for children weighing } \\
\text { between } 46-90 \mathrm{~kg}) \text {. } \\
\text { (Sessions I-4 held twice } \\
\text { per week and sessions } \\
5-10 \text { held weekly) }\end{array}$ & $\begin{array}{l}\text { Diagnosis of OCD } \\
\text { according to ADIS } \\
\text { for DSM-IV: parent } \\
\text { Version (ADIS-IV-P) } \\
\text { and CY-BOCS } \geq 16^{56}\end{array}$ \\
\hline $\begin{array}{l}\text { Farrell } \\
2013^{18}\end{array}$ & $\begin{array}{l}\text { I6 Caucasian, } \\
\text { I Asian }\end{array}$ & 17 & $9 / 8$ & $7 / 10$ & $13.11 \pm 3.33$ & $\begin{array}{l}\text { Each child and adolescent } \\
\text { with difficult-to-treat } \\
\text { OCD took DCS or } \\
\text { placebo ( } 25 \mathrm{mg} \text { for } \\
\text { subjects }<45 \mathrm{~kg} \text {; and } 50 \\
\text { mg for subjects }>46 \mathrm{~kg} \text { ) } \\
\text { I hour prior to each } \\
\text { of ERP sessions } 5-9 . \\
\text { (Total nine sessions held } \\
\text { weekly) }\end{array}$ & $\begin{array}{l}\text { Each subject with } \\
\text { primary diagnosis } \\
\text { of OCD, difficult-to- } \\
\text { treat OCD defined } \\
\text { by an initial dose of } \\
\text { CBT (six + sessions), } \\
\text { including adequate } \\
\text { ERP, with minimal or } \\
\text { no initial response to } \\
\text { treatment, reported } \\
\text { by parents }\end{array}$ \\
\hline $\begin{array}{l}\text { Mataix-Cols } \\
2014^{20}\end{array}$ & - & 27 & $13 / 14$ & $14 / 13$ & $\begin{array}{l}\text { I } 4.7 \pm 2.1 \text { for } \\
\text { DCS group and } \\
15.2 \pm 2.0 \text { for } \\
\text { placebo group }\end{array}$ & $\begin{array}{l}\text { Each subject with OCD } \\
\text { received } 50 \mathrm{mg} \text { DCS } \\
\text { or placebo immediately } \\
\text { after each of the ten } \\
\text { CBT sessions (total } \\
\text { of } 14 \text { sessions over } \\
\text { I7 weeks) }\end{array}$ & $\begin{array}{l}\text { Each with principal } \\
\text { diagnosis of } O C D\end{array}$ \\
\hline
\end{tabular}

Abbreviations: DCS, D-cycloserine; OCD, obsessive compulsive disorder; ERP, exposure and response prevention; DSM-IV, Diagnostic and Statistical Manual of Mental Disorders, fourth edition; DSM-IV-TR, DSM-IV, text revision; Y-BOCS, Yale-Brown Obsessive Compulsive Scale; ADIS-IV-P, ADIS for DSM-IV, parent version; CBT, cognitive behavioral therapy; ADIS, Anxiety Disorder Interview Schedule; CY-BOCS, Children's Yale-Brown Obsessive Compulsive Scale; SD, standard deviation. 
Table 2 Studies included in the meta-analysis of effect of DCS on the Y-BOCS at midtreatment

\begin{tabular}{|c|c|c|c|c|c|c|c|c|c|}
\hline \multirow{2}{*}{$\begin{array}{l}\text { First } \\
\text { author }\end{array}$} & \multicolumn{4}{|l|}{ DCS group } & \multicolumn{4}{|l|}{ Placebo group } & \multirow[t]{2}{*}{ Notes } \\
\hline & Pretreatment & Midtreatment & Decrease & $\begin{array}{l}\text { Sample } \\
\text { size }(n)\end{array}$ & Pretreatment & Midtreatment & Decrease & $\begin{array}{l}\text { Sample } \\
\text { size }(n)\end{array}$ & \\
\hline $\begin{array}{l}\text { Kushner } \\
2007^{17}\end{array}$ & $27.1 \pm 3.8$ & $\mid 5.1 \pm 4.8$ & $12.0 \pm 6.1$ & 14 & $28.2 \pm 5.1$ & $15.5 \pm 6.2$ & $12.7 \pm 8.0$ & 11 & $\begin{array}{l}\text { Y-BOCS was given } \\
\text { at baseline and after } \\
\text { fourth session }\end{array}$ \\
\hline $\begin{array}{l}\text { Wilhelm } \\
2008^{16}\end{array}$ & $26.5 \pm 5.0$ & $12.8 \pm 6.3$ & $13.7 \pm 8.0$ & 10 & $25.5 \pm 4.2$ & $19.0 \pm 4.1$ & $6.5 \pm 5.9$ & 13 & $\begin{array}{l}\text { Y-BOCS was given } \\
\text { at pretreatment and } \\
\text { after fifth session }\end{array}$ \\
\hline $\begin{array}{l}\text { Storch } \\
2010^{19}\end{array}$ & $24.1 \pm 4.4$ & $15.6 \pm 6.8$ & $8.5 \pm 8.1$ & 15 & $26.0 \pm 3.8$ & $17.9 \pm 4.5$ & $8.1 \pm 5.9$ & 15 & $\begin{array}{l}\text { CY-BOCS was given } \\
\text { at pretreatment and } \\
\text { after sixth session }\end{array}$ \\
\hline $\begin{array}{l}\text { Mataix-Cols } \\
2014^{20}\end{array}$ & $26.9 \pm 3.7$ & $18.1 \pm 7.6$ & $8.8 \pm 8.5$ & 13 & $25.0 \pm 3.4$ & $17.5 \pm 4.6$ & $7.5 \pm 5.7$ & 14 & - \\
\hline
\end{tabular}

Note: Data are presented as mean \pm standard deviation unless noted otherwise.

Abbreviations: DCS, D-cycloserine; Y-BOCS, Yale-Brown Obsessive Compulsive Scale; CY-BOCS, Children's Yale-Brown Obsessive Compulsive Scale.

subjects at midtreatment using a random-effect model did not reveal significant difference between the two, although patients in both groups experienced a sharp decrease of Y-BOCS value at midtreatment; further, DCS-augmented ERP therapy did show a trend toward significantly lower Y-BOCS value and significantly greater Y-BOCS decrease at midtreatment compared to placebo-augmented ERP therapy; wherein, said trend was more pronounced in the subpopulation of DCS taken prior to each of the ERP sessions: $(\mathrm{MD}=-2.12 ; 95 \% \mathrm{CI}=[-4.99,0.75] ; P=0.15$; $\left.I^{2}=40\right)$ for whole population; $(\mathrm{MD}=-3.29 ; 95 \% \mathrm{CI}=[-8.97$, 2.39]; $\left.P=0.07 ; P^{2}=0.69\right)$ for the subpopulation of DCS taken before each of the ERP sessions for analysis of DCS and $\mathrm{Y}$-BOCS value at midtreatment (Figure 2); and $(\mathrm{MD}=1.91$; $\left.95 \% \mathrm{CI}=[-1.39,5.21] ; P=0.26 ; P^{2}=30\right)$ for whole population and $(\mathrm{MD}=3.21 ; 95 \% \mathrm{CI}=[-4.53,10.95] ; P=0.42$; $I^{2}=72$ ) for the subpopulation of DCS taken before each of the ERP sessions for the analysis of DCS and decrease of

Table 3 Studies included in the meta-analysis of effect of DCS on the Y-BOCS at posttreatment

\begin{tabular}{|c|c|c|c|c|c|c|c|c|c|}
\hline \multirow{2}{*}{$\begin{array}{l}\text { First } \\
\text { author }\end{array}$} & \multicolumn{4}{|l|}{ DCS group } & \multicolumn{4}{|l|}{ Placebo group } & \multirow[t]{2}{*}{ Notes } \\
\hline & Pretreatment & Posttreatment & Decrease & $\begin{array}{l}\text { Sample } \\
\text { size }(n)\end{array}$ & Pretreatment & Posttreatment & Decrease & $\begin{array}{l}\text { Sample } \\
\text { size }(n)\end{array}$ & \\
\hline $\begin{array}{l}\text { Kushner } \\
2007^{17}\end{array}$ & $27.1 \pm 3.8$ & $10.9 \pm 4.7$ & $16.2 \pm 6.0$ & 14 & $28.2 \pm 5.1$ & $11.2 \pm 6.8$ & $17.0 \pm 8.5$ & 11 & $\begin{array}{l}\text { Y-BOCS was } \\
\text { given at baseline } \\
\text { and at last session } \\
\text { (tenth session) }\end{array}$ \\
\hline $\begin{array}{l}\text { Storch } \\
2007^{8}\end{array}$ & $30.1 \pm 3.8$ & $10.1 \pm 6.8$ & $20 \pm 7.8$ & 12 & $30.6 \pm 4.9$ & $8.6 \pm 8.8$ & $22 \pm 10.1$ & 12 & $\begin{array}{l}\text { Y-BOCS was given } \\
\text { before treatment } \\
\text { and I week } \\
\text { posttreatment }\end{array}$ \\
\hline $\begin{array}{l}\text { Wilhelm } \\
2008^{16}\end{array}$ & $26.5 \pm 5.0$ & $10.2 \pm 7.2$ & $16.3 \pm 8.8$ & 10 & $25.5 \pm 4.2$ & $14.5 \pm 6.4$ & II $.0 \pm 7.7$ & 13 & $\begin{array}{l}\text { Y-BOCS was given } \\
\text { at pretreatment and } \\
\text { after tenth session }\end{array}$ \\
\hline $\begin{array}{l}\text { Storch } \\
2010^{19}\end{array}$ & $24.1 \pm 4.4$ & $6.8 \pm 6.0$ & $17.3 \pm 7.4$ & 15 & $26.0 \pm 3.8$ & $11.0 \pm 6.6$ & $15.0 \pm 7.6$ & 15 & $\begin{array}{l}\text { CY-BOCS was given } \\
\text { at pretreatment } \\
\text { and within I week } \\
\text { posttreatment }\end{array}$ \\
\hline $\begin{array}{l}\text { Farrell } \\
2013^{18}\end{array}$ & $30 \pm 5.47$ & $13.78 \pm 5.3$ & $16.22 \pm 7.62$ & 9 & $28.88 \pm 5.8$ & $13.75 \pm 7.70$ & $15.13 \pm 9.64$ & 8 & $\begin{array}{l}\text { CY-BOCS was given } \\
\text { at pretreatment and } \\
\text { posttreatment }\end{array}$ \\
\hline $\begin{array}{l}\text { Mataix-Cols } \\
2014^{20}\end{array}$ & $26.9 \pm 3.7$ & $10.6 \pm 7.4$ & $16.3 \pm 8.3$ & 13 & $25.0 \pm 3.4$ & $10.1 \pm 6.1$ & $14.9 \pm 6.9$ & 14 & $\begin{array}{l}\text { CY-BOCS was given } \\
\text { at pretreatment and } \\
\text { end of treatment }\end{array}$ \\
\hline
\end{tabular}

Note: Data are presented as mean \pm standard deviation unless noted otherwise.

Abbreviations: DCS, D-cycloserine; Y-BOCS, Yale-Brown Obsessive Compulsive Scale; CY-BOCS, Children's Yale-Brown Obsessive Compulsive Scale. 
Table 4 Studies included in the meta-analysis of effect of DCS on the Y-BOCS at 3-month follow-up

\begin{tabular}{|c|c|c|c|c|c|c|c|c|c|}
\hline \multirow{2}{*}{$\begin{array}{l}\text { First } \\
\text { author }\end{array}$} & \multicolumn{4}{|l|}{ DCS group } & \multicolumn{4}{|l|}{ Placebo group } & \multirow[t]{2}{*}{ Notes } \\
\hline & Pretreatment & $\begin{array}{l}\text { 3-month } \\
\text { follow-up }\end{array}$ & Decrease & $\begin{array}{l}\text { Sample } \\
\text { size (n) }\end{array}$ & Pretreatment & $\begin{array}{l}\text { 3-month } \\
\text { follow-up }\end{array}$ & Decrease & $\begin{array}{l}\text { Sample } \\
\text { size }(n)\end{array}$ & \\
\hline $\begin{array}{l}\text { Kushner } \\
2007^{17}\end{array}$ & $27.1 \pm 3.8$ & $12.3 \pm 7.2$ & $|4.8 \pm 8|$. & 14 & $28.2 \pm 5.1$ & $11.3 \pm 6.7$ & $16.9 \pm 8.4$ & 11 & $\begin{array}{l}\text { Y-BOCS was given } \\
\text { at baseline and at } \\
\text { 3-month follow-up }\end{array}$ \\
\hline $\begin{array}{l}\text { Storch } \\
2007^{8}\end{array}$ & $30.1 \pm 3.8$ & $10.3 \pm 6.6$ & $19.8 \pm 7.6$ & 12 & $30.6 \pm 4.9$ & $7.9 \pm 6.8$ & $22.7 \pm 8.4$ & 11 & $\begin{array}{l}\text { Y-BOCS was given } \\
\text { before treatment and } \\
\text { 3-month follow-up }\end{array}$ \\
\hline $\begin{array}{l}\text { Farrell } \\
2013^{18}\end{array}$ & $30 \pm 5.47$ & $10.14 \pm 7.69$ & $19.86 \pm 9.44$ & 9 & $28.88 \pm 5.8$ & $13.00 \pm 6.76$ & $|5.88 \pm 8.9|$ & 8 & $\begin{array}{l}\text { CY-BOCS was given at } \\
\text { pretreatment, I- and } \\
\text { 3-month follow-ups }\end{array}$ \\
\hline $\begin{array}{l}\text { Mataix-Cols } \\
2014^{20}\end{array}$ & $26.9 \pm 3.7$ & $9.3 \pm 11.2$ & $17.6 \pm 1 \mid .8$ & 13 & $25.0 \pm 3.4$ & $8.5 \pm 6.2$ & $16.5 \pm 7.1$ & 14 & $\begin{array}{l}\text { CY-BOCS was given } \\
\text { at pretreatment and } \\
\text { 3-month follow-up }\end{array}$ \\
\hline
\end{tabular}

Note: Data are presented as mean \pm standard deviation unless noted otherwise.

Abbreviations: DCS, D-cycloserine; Y-BOCS, Yale-Brown Obsessive Compulsive Scale; CY-BOCS, Children's Yale-Brown Obsessive Compulsive Scale.

Y-BOCS at midtreatment (Figure 3). These results suggest that when measured at midtreatment, although not significant, DCS may enhance the efficacy of ERP therapy in reducing OCD symptomatic severity in OCD subjects, especially when the DCS was taken prior to each of the ERP sessions.

\section{Sensitivity analysis, heterogeneity, and publication bias}

Both meta-analyses comparing the effects of DCSaugmented therapy and placebo-augmented therapy on the Y-BOCS value and decrease of Y-BOCS value of the OCD subjects at midtreatment were robust to sensitivity analysis, with overall $P$-value remaining insignificant when each of the included studies was individually removed from the analysis (data not shown).
Heterogeneity for both meta-analyses was low to moderate, with $I^{2}$ values of 40 and 30 for the analysis of DCS and Y-BOC value and of DCS and decrease of Y-BOCS value, respectively (Figures 3 and 4). Further, funnel plots used to evaluate publication bias for the analyses were both symmetrical, indicating none or very little publication bias for the two meta-analysis (data not shown).

\section{Meta-analyses of DCS and Y-BOCS at posttreatment}

Meta-analyses comparing the effects of DCS-augmented ERP therapy and placebo-augmented ERP therapy on the Y-BOCS value and decrease of Y-BOCS value of the OCD subjects at posttreatment using a fixed-effect model did not reveal significant difference between

Table 5 Studies included in the meta-analysis of effect of DCS on the CGI-S at posttreatment

\begin{tabular}{|c|c|c|c|c|c|c|c|c|c|}
\hline \multirow{2}{*}{$\begin{array}{l}\text { First } \\
\text { author }\end{array}$} & \multicolumn{4}{|l|}{ DCS group } & \multicolumn{4}{|l|}{ Placebo group } & \multirow[t]{2}{*}{ Notes } \\
\hline & Pretreatment & Posttreatment & Decrease & $\begin{array}{l}\text { Sample } \\
\text { size }(n)\end{array}$ & Pretreatment & Posttreatment & Decrease & $\begin{array}{l}\text { Sample } \\
\text { size }(n)\end{array}$ & \\
\hline $\begin{array}{l}\text { Storch } \\
2007^{8}\end{array}$ & $4.3 \pm 0.8$ & $1.8 \pm 1.1$ & $2.5 \pm 1.4$ & 12 & $4.3 \pm 1.1$ & $1.6 \pm 1.4$ & $2.7 \pm 1.8$ & 12 & $\begin{array}{l}\text { CGI-S was assessed } \\
\text { before treatment and } \\
\text { I week posttreatment }\end{array}$ \\
\hline $\begin{array}{l}\text { Storch } \\
2010^{19}\end{array}$ & $4.6 \pm 0.83$ & $2.0 \pm 1.0$ & $2.6 \pm 1.3$ & 15 & $5.1 \pm 0.74$ & $3.0 \pm 1.2$ & $2.1 \pm 1.4$ & 15 & $\begin{array}{l}\text { CGI-S was assessed } \\
\text { before treatment } \\
\text { and within I week } \\
\text { posttreatment }\end{array}$ \\
\hline $\begin{array}{l}\text { Farrell } \\
2013^{18}\end{array}$ & $5.67 \pm 0.70$ & $3.00 \pm 1.65$ & $2.67 \pm 1.79$ & 9 & $5.38 \pm 0.7$ & $2.63 \pm 1.30$ & $2.75 \pm 1.48$ & 8 & $\begin{array}{l}\text { CGI-S was assessed } \\
\text { before treatment and } \\
\text { posttreatment }\end{array}$ \\
\hline
\end{tabular}

Note: Data are presented as mean \pm standard deviation unless noted otherwise.

Abbreviations: DCS, D-cycloserine; CGI-S, Clinical Global Impression - Severity Scale. 
Table 6 Studies included in the meta-analysis of the effect of DCS on proportion of responders at posttreatment

\begin{tabular}{|c|c|c|c|c|c|c|c|}
\hline \multirow{2}{*}{$\begin{array}{l}\text { First } \\
\text { author }\end{array}$} & \multicolumn{3}{|l|}{ DCS group } & \multicolumn{3}{|c|}{ Placebo group } & \multirow[t]{2}{*}{ Notes } \\
\hline & $\begin{array}{l}\text { Responders } \\
\text { (N) }\end{array}$ & $\begin{array}{l}\text { Nonresponders } \\
\text { (N) }\end{array}$ & $\begin{array}{l}\text { Total } \\
\text { (N) }\end{array}$ & $\begin{array}{l}\text { Responders } \\
\text { (N) }\end{array}$ & $\begin{array}{l}\text { Nonresponders } \\
\text { (N) }\end{array}$ & $\begin{array}{l}\text { Total } \\
\text { (N) }\end{array}$ & \\
\hline $\begin{array}{l}\text { Storch } \\
2007^{8}\end{array}$ & 10 & 1 & 12 & 11 & 1 & 12 & $\begin{array}{l}\text { Responders defined as } \\
\text { obtaining a CGI scale }{ }^{57} \text { score } \\
\text { of "very much improved" or } \\
\text { "much improved" at I-week } \\
\text { posttreatment }\end{array}$ \\
\hline $\begin{array}{l}\text { Farrell } \\
2013^{18}\end{array}$ & 9 & 0 & 9 & 7 & 1 & 8 & $\begin{array}{l}\text { Responder defined by }>25 \% \\
\text { reduction on CY-BOCS at } \\
\text { posttreatment }\end{array}$ \\
\hline $\begin{array}{l}\text { Mataix-Cols } \\
2014^{20}\end{array}$ & 8 & 5 & 13 & 9 & 5 & 14 & $\begin{array}{l}\text { Responder defined as } \geq 35 \% \\
\text { reduction on the CY-BOCS } \\
\text { at end of treatment }\end{array}$ \\
\hline
\end{tabular}

Abbreviations: DCS, D-cycloserine; CGI, Clinical Global Impression - Severity Scale; CY-BOCS, Children's Yale-Brown Obsessive Compulsive Scale.

the two, although patients in both groups experienced a sharp decrease of Y-BOCS value at posttreatment; further, although less obvious than midtreatment, DCSaugmented therapy did show a trend toward significantly lower Y-BOCS value and significantly greater Y-BOCS decrease at posttreatment compared to placebo-enhanced therapy, wherein said trend was more pronounced in the subpopulation of DCS taken prior to some of the ERP sessions: $(\mathrm{MD}=-1.39 ; 95 \% \mathrm{CI}=[-3.56,0.78] ; P=0.21$; $R^{2}=0$ ) for whole population for analysis of DCS and Y-BOCS value at posttreatment and $(\mathrm{MD}=-2.78 ; 95 \% \mathrm{CI}=[-6.46$, $0.90] ; P=0.14 ; I^{2}=11$ ) for the subpopulation of DCS taken before some of ERP sessions (Figure $3 \mathrm{~A})$; and $(\mathrm{MD}=1.27$; $\left.95 \% \mathrm{CI}=[-1.33,3.87] ; P=0.34 ; I^{2}=0\right)$ for whole population for analysis of DCS and decreases of Y-BOCS value at posttreatment and $(\mathrm{MD}=1.95 ; 95 \% \mathrm{CI}=[-2.57,6.46]$; $\left.P=0.40 ; I^{2}=0\right)$ for the subpopulation of DCS taken before some of ERP sessions (Figure 3B). These results suggest that when measured at posttreatment, although not significant, DCS may enhance the efficacy of ERP therapy in reducing the OCD symptomatic severity in OCD subjects, especially when the DCS was taken prior to some of the ERP sessions; however, said enhancement was less pronounced than midtreatment.

\section{Sensitivity analysis, heterogeneity, and publication bias}

Both meta-analyses comparing the effects of DCS-augmented therapy and placebo-augmented therapy on the Y-BOCS value and decrease of the Y-BOCS value of the OCD subjects at posttreatment were robust to sensitivity analysis, with overall $P$-value remaining insignificant when each of the included studies was individually removed from the analysis (data not shown).

Table 7 Studies included in meta-analysis of the effect of DCS on the proportion of patients meeting remission status criteria at posttreatment

\begin{tabular}{|c|c|c|c|c|c|c|c|}
\hline \multirow{2}{*}{$\begin{array}{l}\text { First } \\
\text { author }\end{array}$} & \multicolumn{3}{|l|}{ DCS group } & \multicolumn{3}{|c|}{ Placebo group } & \multirow[t]{2}{*}{ Notes } \\
\hline & $\begin{array}{l}\text { Remission } \\
\text { (N) }\end{array}$ & $\begin{array}{l}\text { Not remission } \\
\text { (N) }\end{array}$ & $\begin{array}{l}\text { Total } \\
(\mathrm{N})\end{array}$ & $\begin{array}{l}\text { Remission } \\
\text { (N) }\end{array}$ & $\begin{array}{l}\text { Not remission } \\
\text { (N) }\end{array}$ & $\begin{array}{l}\text { Total } \\
\text { (N) }\end{array}$ & \\
\hline $\begin{array}{l}\text { Storch } \\
2007^{8}\end{array}$ & 5 & 7 & 12 & 7 & 5 & 12 & $\begin{array}{l}\text { Remission defined as having a } \\
\text { severity rating on the ADIS-IV } \leq 3 \\
\text { and CY-BOCS total score } \leq 10 \\
\text { assessed at } \text { I-week posttreatment }\end{array}$ \\
\hline $\begin{array}{l}\text { Farrell } \\
2013^{18}\end{array}$ & 5 & 4 & 9 & 4 & 4 & 8 & $\begin{array}{l}\text { Remission defined by }>50 \% \\
\text { reduction on the CY-BOCS } \\
\text { combined with a CY-BOCS score } \\
\text { of }<14 \text { ) at posttreatment }\end{array}$ \\
\hline $\begin{array}{l}\text { Mataix-Cols } \\
2014^{20}\end{array}$ & 7 & 6 & 13 & 6 & 8 & 14 & $\begin{array}{l}\text { Remission defined as CY-BOCS } \\
\text { scores } \leq 10 \text { at posttreatment }\end{array}$ \\
\hline
\end{tabular}

Abbreviations: ADIS-IV, ADIS for Diagnostic and Statistical Manual of Mental Disorders, fourth edition; DCS, D-cycloserine; CY-BOCS, Children's Yale-Brown Obsessive Compulsive Scale. 


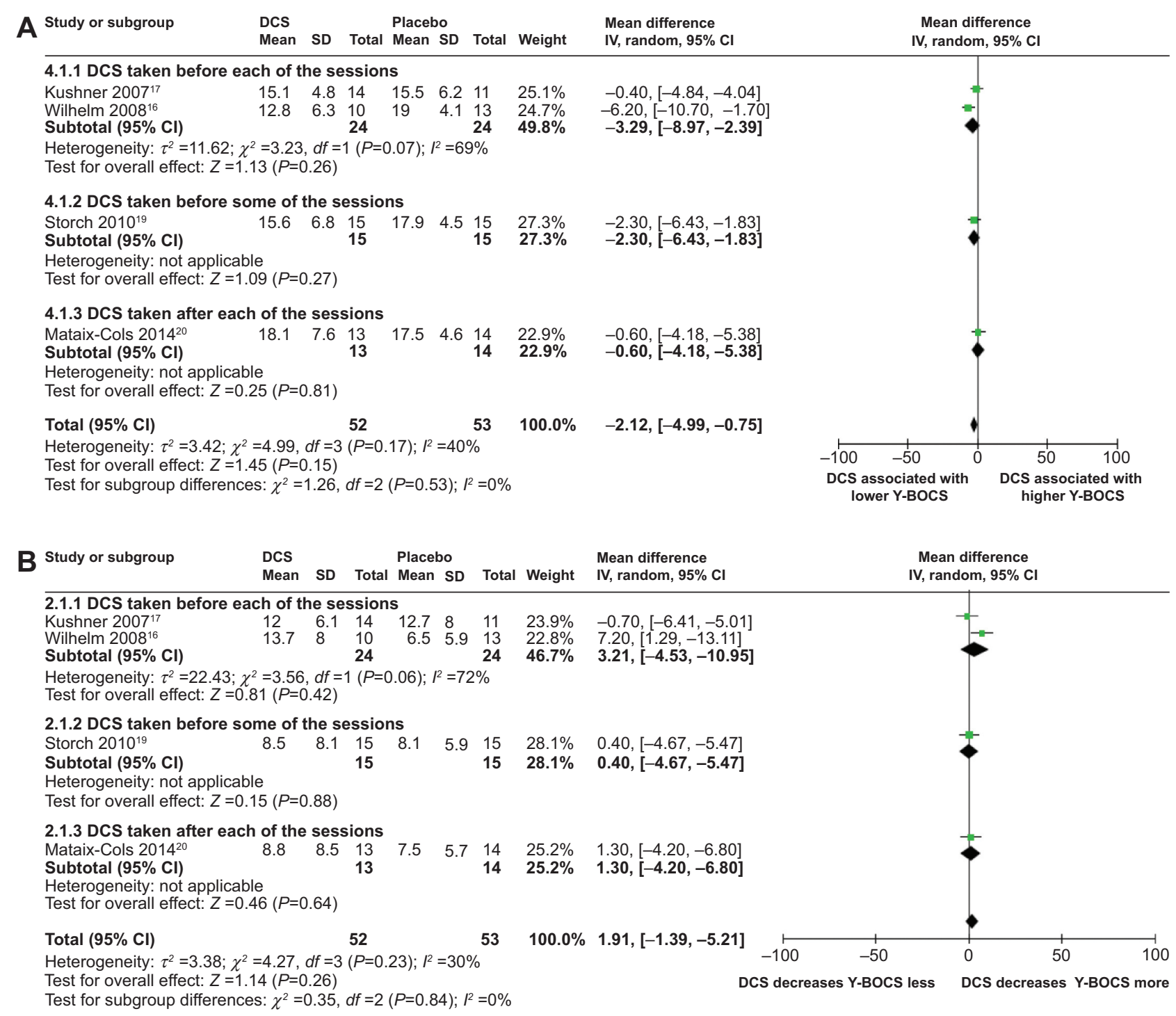

Figure 2 Forest plots of the effect of DCS versus placebo on Y-BOCS value or on deceasing Y-BOCS values of the patients receiving behavioral therapy at midtreatment. Notes: (A) Forest plot of comparison of the effect of the DCS and placebo on the Y-BOCS value of the patients receiving behavioral therapy at midtreatment; overall effect for continuous outcome (random-effect model). The diamond stood for pooled effect. No significant difference between the effect of DCS and placebo on Y-BOCS value of the patients receiving behavioral therapy at midtreatment, although DCS-augmented behavioral therapy showed a trend toward significantly lower Y-BOCS value compared to placebo-augmented behavioral therapy. (B) Forest plot of comparison of the effect of DCS and placebo on decreasing Y-BOCS of the patients receiving behavioral therapy at midtreatment; overall effect for continuous outcome (random-effect model). The diamond stood for pooled effect. No significant difference between the effect of DCS and placebo on decreasing Y-BOCS of the patients receiving behavioral therapy at midtreatment, although DCS-augmented behavioral therapy showed a trend toward significantly greater Y-BOCS decrease compared to placebo-augmented behavioral therapy.

Abbreviations: DCS, D-cycloserine; Y-BOCS, Yale-Brown Obsessive Compulsive Scale; Cl, confidence interval; SD, standard deviation; IV, inverse variance; df, degrees of freedom.

Neither meta-analyses had heterogeneity (Figure 3A and B). Further funnel plots used to evaluate publication bias for the analyses were both symmetrical, indicating none or very little publication bias for the meta-analyses (data not shown).

\section{Meta-analyses of DCS and Y-BOCS at 3-month follow-up}

Meta-analyses comparing the effects of DCS-augmented ERP therapy and placebo-augmented ERP therapy on the Y-BOCS value and decrease of Y-BOCS value of the OCD subjects at 3-month follow-up using a fixed-effect model did not reveal significant difference between the two, although patients in both the DCS group and the placebo group experienced a sharp decrease of Y-BOCS value at posttreatment: $\left(\mathrm{MD}=0.64 ; 95 \% \mathrm{CI}=[-2.39,3.67] ; P=0.68 ; P^{2}=0\right)$ for analysis of DCS and Y-BOCS value at 3-month follow-up (Figure 4A); and $\left(\mathrm{MD}=-0.57 ; 95 \% \mathrm{CI}=[-4.15,3.01] ; P=0.31 ; I^{2}=0\right)$ for analysis of DCS and decreases of Y-BOCS value at 3-month follow-up (Figure 4B). This result suggested that measured at the 3-month follow-up, the DCS-augmented therapy did not 


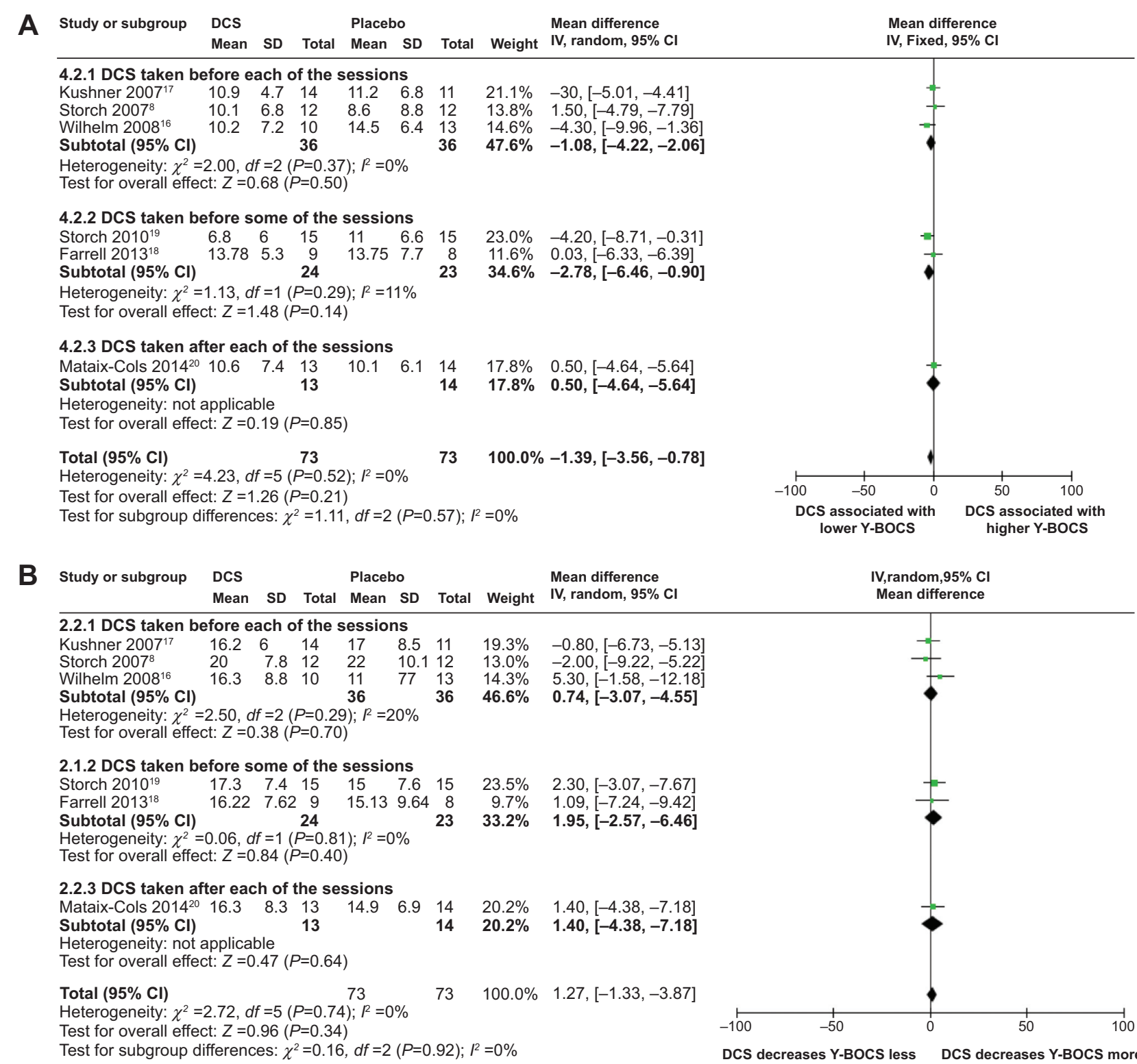

Figure 3 Forest plots of the effect of DCS versus placebo on Y-BOCS value or on deceasing Y-BOCS values of the patients receiving behavioral therapy at posttreatment. Notes: (A) Forest plot of comparison of the effect of DCS and placebo on Y-BOCS value of the patients receiving behavioral therapy at posttreatment; overall effect for continuous outcome (fixed-effect model). The diamond stood for pooled effect. No significant difference between the effect of DCS and placebo on Y-BOCS value of the patients receiving behavioral therapy at posttreatment. (B) Forest plot of comparison of the effect of DCS and placebo on decreasing Y-BOCS of the patients receiving behavioral therapy at posttreatment; overall effect for continuous outcome (fixed-effect model). The diamond stood for pooled effect. No significant difference between the effect of DCS and placebo on decreasing Y-BOCS of the patients receiving behavioral therapy at posttreatment.

Abbreviations: DCS, D-cycloserine; Y-BOCS, Yale-Brown Obsessive Compulsive Scale; CI, confidence interval; SD, standard deviation; IV, inverse variance; df, degrees of freedom.

show advantage in reducing the OCD symptomatic severity in OCD patients compared to placebo-augmented therapy.

\section{Sensitivity analysis, heterogeneity, and publication bias}

Both meta-analyses comparing the effects of DCS-augmented therapy and placebo-augmented therapy on the Y-BOCS value and decrease of Y-BOCS value of the OCD subjects at the 3-month follow-up were robust to sensitivity analysis, with the overall $P$-value remaining insignificant when each of the included studies was removed individually from the analysis (data not shown).

Neither meta-analyses had heterogeneity (Figure 4A and B). Further funnel plots used to evaluate publication bias for both analyses were both symmetrical, indicating none or very little publication bias for the meta-analyses (data not shown). 


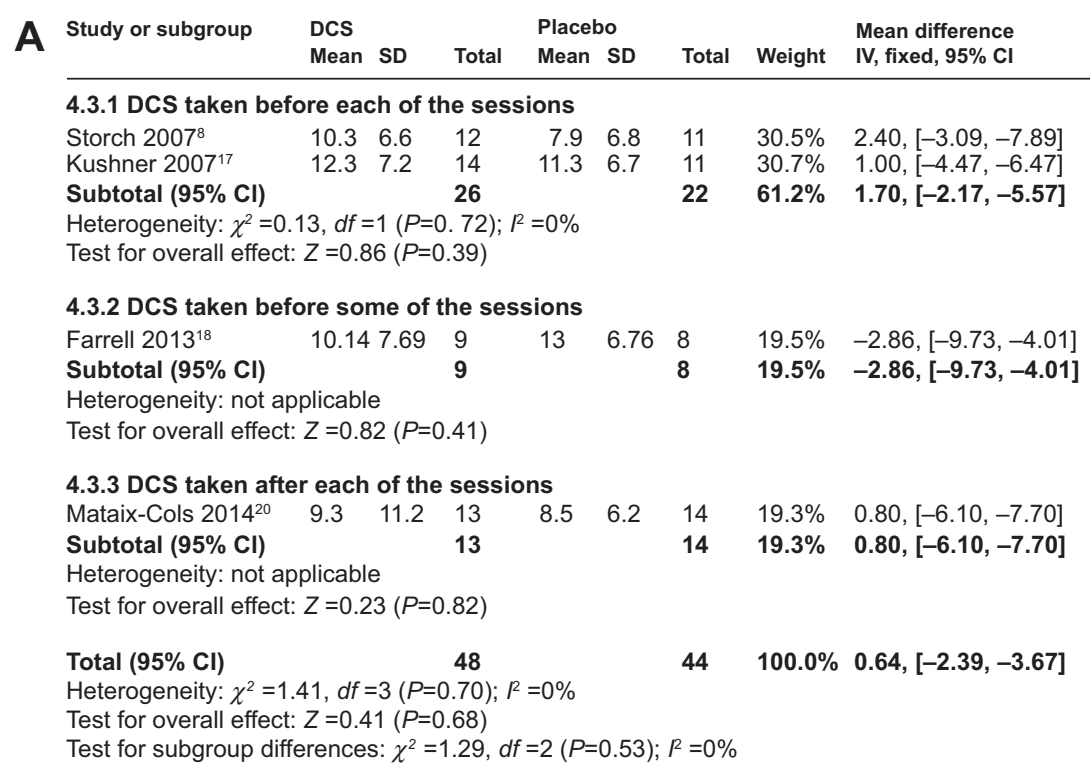

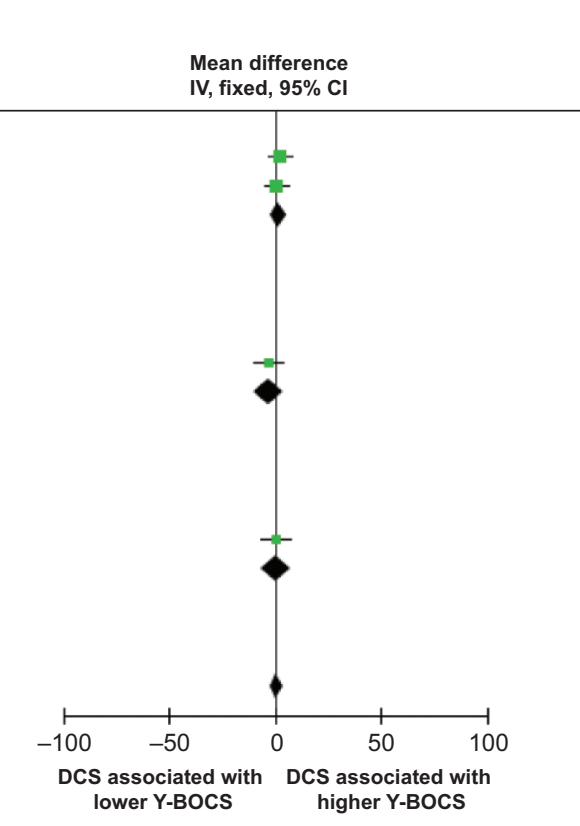

\begin{tabular}{|c|c|c|c|c|c|c|c|c|}
\hline Study or subgroup & $\begin{array}{l}\text { DCS } \\
\text { Mean }\end{array}$ & SD & Total & $\begin{array}{l}\text { Placebo } \\
\text { Mean }\end{array}$ & SD & Total & Weight & $\begin{array}{l}\text { Mean difference } \\
\text { IV, fixed, } 95 \% \mathrm{CI}\end{array}$ \\
\hline \multicolumn{9}{|c|}{ 2.3.1 DCS taken before each of the sessions } \\
\hline Kushner $2007^{17}$ & 14.8 & 8.1 & 14 & 16.9 & 8.4 & 11 & $30.1 \%$ & $-2.10,[-8.63,-4.43]$ \\
\hline Storch $2007^{8}$ & 19.8 & 7.6 & 12 & 22.7 & 8.4 & 11 & $29.7 \%$ & $-2.90,[-9.47,-3.67]$ \\
\hline Subtotal $(95 \% \mathrm{Cl})$ & & & 26 & & & 22 & $59.8 \%$ & $-2.50,[-7.13,-2.13]$ \\
\hline
\end{tabular}

Heterogeneity: $\chi^{2}=0.03, d f=1(P=0.87) ; P^{2}=0 \%$

Test for overall effect: $Z=1.06(P=0.29)$

\subsubsection{DCS taken before some of the sessions}

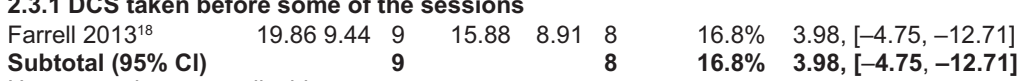

Heterogeneity: not applicable

Test for overall effect: $Z=0.89(P=0.37)$

2.3.1 DCS taken after each of the sessions

$\begin{array}{lllll}\text { Mataix-Cols } 2014^{20} & 17.6 & 11.8 & 13 & 16.5\end{array}$

Subtotal $(95 \% \mathrm{Cl})$

Heterogeneity: not applicable

Test for overall effect: $Z=0.29(P=0.77)$

Total $(95 \% \mathrm{Cl})$

Heterogeneity: $\chi^{2}=1.93, d f=3(P=0.59) ; l^{2}=0 \%$

Test for overall effect: $Z=0.31(P=0.76)$

Test for subgroup differences: $\chi^{2}=1.90, d f=2(P=0.39), l^{2}=0 \%$

$\begin{array}{llll}7.1 & 14 & 23.3 \% & 1.10,[-6.31,-8.51] \\ & 14 & \mathbf{2 3 . 3} \% & \mathbf{1 . 1 0},[-6.31,-8.51]\end{array}$

$44 \quad 100.0 \%-0.57,[-4.15,-3.01]$

10

$-100-50$

DCS decreases Y-BOCS less
Mean difference

IV, fixed, $95 \% \mathrm{CI}$

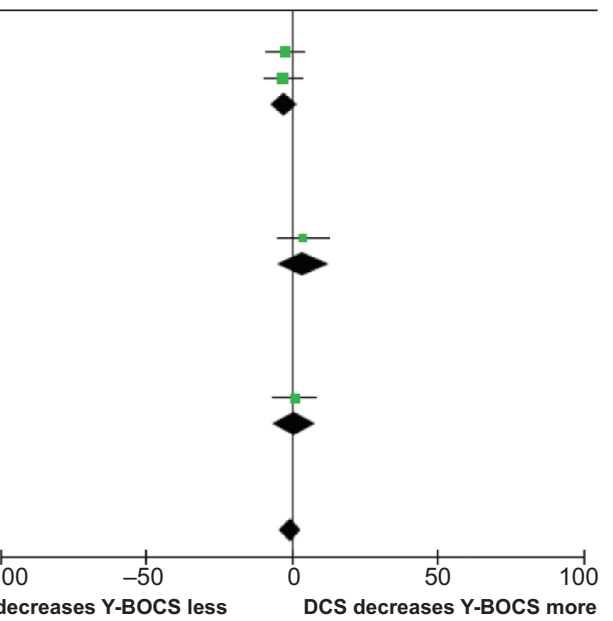

Figure 4 Forest plots of the effect of DCS versus placebo on Y-BOCS value or on deceasing Y-BOCS values of the patients receiving behavioral therapy at 3-month follow-up. Notes: (A) Forest plot of comparison of the effect of DCS and placebo on Y-BOCS value of the patients receiving behavioral therapy at 3-month follow-up; overall effect for continuous outcome (fixed-effect model). The diamond stood for pooled effect. No significant difference between the effect of DCS and placebo on Y-BOCS value of the patients receiving behavioral therapy at 3-month follow-up. (B) Forest plot of comparison of the effect of DCS and placebo on decreasing Y-BOCS of the patients receiving behavioral therapy at 3-month follow-up; overall effect for continuous outcome (fixed-effect model). The diamond stood for pooled effect. No significant difference between the effect of DCS and placebo on decreasing Y-BOCS of the patients receiving behavioral therapy at 3-month follow-up.

Abbreviations: DCS, D-cycloserine; Y-BOCS, Yale-Brown Obsessive Compulsive Scale; Cl, confidence interval; SD, standard deviation; IV, inverse variance; df, degrees of freedom.

\section{Meta-analyses of DCS and CGI-S at posttreatment}

Meta-analyses comparing the effects of DCS-augmented therapy and placebo-augmented therapy on the CGI-S value and decrease of CGI-S value of the OCD subjects at posttreatment using a random-effect model and a fixedeffect model, respectively, did not reveal significant difference between the two, although patients in both the DCS group and the placebo group experienced a sharp decrease of CGI-S value at posttreatment: (MD $=-0.25 ; 95 \%$ $\left.\mathrm{CI}=[-1.17,0.68] ; P=0.60 ; I^{2}=58\right)$ for analysis of DCS and CGI-S value at posttreatment (Figure $5 \mathrm{~A}$ ); and (MD $=0.18$; $\left.95 \% \mathrm{CI}=[-0.51,0.88] ; P=0.60 ; I^{2}=0\right)$ for the analysis of the DCS and the decreases of the CGI-S value at posttreatment (Figure 4B). This result suggested that at the 3-month follow-up, DCS-augmented therapy did not show the advantage in reducing OCD symptomatic severity in OCD patients compared to placebo-augmented therapy. 


\section{Sensitivity analysis, heterogeneity, and publication bias}

Both the meta-analyses comparing the effects of DCSaugmented therapy and the placebo-augmented therapy on the CGI-S value and the decrease of the CGI-S value of the OCD subjects at posttreatment were robust to sensitivity analysis, with overall $P$-value remaining insignificant when each of the included studies was individually removed from the analysis (data not shown).

The meta-analysis comparing the effects of DCSaugmented therapy and placebo-augmented therapy on the CGI-S value had moderate heterogeneity with an $I^{2}=58$ (Figure 5A), while the meta-analysis comparing the effects of DCS-augmented therapy and placebo-augmented therapy on decrease of the CGI-S value did not have heterogeneity (Figure 5B). Further funnel plots used to evaluate publication bias for both analyses were both symmetrical, indicating none or very little publication bias for the meta-analyses (data not shown).

\section{Meta-analyses of DCS and proportion of treatment responders and of DCS and proportions of subjects attaining clinical remission status criteria at posttreatment}

Meta-analysis comparing efficacies of DCS-augmented ERP therapy and placebo-augmented ERP therapy in increased proportions of treatment responders and subjects attaining clinical remission status criteria at posttreatment using a fixed-effect model did not reveal a significant difference between the two groups, although a majority of patients in

\begin{tabular}{|c|c|c|c|c|c|c|}
\hline Study or subgroup & $\begin{array}{l}\text { DCS } \\
\text { Mean }\end{array}$ & SD & Total & $\begin{array}{l}\text { Placeb } \\
\text { Mean }\end{array}$ & o $\mathrm{SD}$ & Total \\
\hline \multicolumn{7}{|c|}{ 5.1.1 DCS taken before each of the sessions } \\
\hline $\begin{array}{l}\text { Storch } 2007^{8} \\
\text { Storch } 2010^{19}\end{array}$ & $\begin{array}{l}1.8 \\
2\end{array}$ & $\begin{array}{l}1.1 \\
1\end{array}$ & $\begin{array}{l}12 \\
15\end{array}$ & $\begin{array}{l}1.6 \\
3\end{array}$ & $\begin{array}{l}1.4 \\
1.2\end{array}$ & $\begin{array}{l}12 \\
15\end{array}$ \\
\hline $\begin{array}{l}\text { Subtotal }(95 \% \mathrm{CI}) \\
\text { Heterogeneity: } \tau^{2}=c \\
\text { Test for overall effec }\end{array}$ & $\begin{array}{l}1 ; \chi^{2}=3 \\
=0.74\end{array}$ & $\begin{array}{l}37, d \\
P=0 .\end{array}$ & $\begin{array}{l}27 \\
\text { If }=1 \\
46)\end{array}$ & $=0.07)$; & $I^{2}=70$ & $\begin{array}{r}27 \\
0 \%\end{array}$ \\
\hline \multicolumn{7}{|c|}{ 5.1.2 DCS taken before each of the sessions $5-9$} \\
\hline Farrell $2013^{18}$ & 3 & 1.65 & & 2.63 & 1.3 & 8 \\
\hline $\begin{array}{l}\text { Subtotal }(95 \% \mathrm{CI}) \\
\text { Heterogeneity: not a } \\
\text { Test for overall effec }\end{array}$ & icable & $P=0$ & 61) & & & 8 \\
\hline $\begin{array}{l}\text { Total }(95 \% \mathrm{Cl}) \\
\text { Heterogeneity: } \tau^{2}=c\end{array}$ & $; \chi^{2}=4$ & 70 & $\begin{array}{c}36 \\
f f=2(P\end{array}$ & $=0.09$ ); & $2=58$ & $\begin{array}{l}35 \\
8 \%\end{array}$ \\
\hline $\begin{array}{l}\text { Test for overall effec } \\
\text { Test for subgroup di }\end{array}$ & $\begin{array}{l}=0.53 \\
\text { ences: }\end{array}$ & $\begin{array}{l}P=0 . \\
\chi^{2}=0 .\end{array}$ & $\begin{array}{l}\text { 60) } \\
76, d f\end{array}$ & & & \\
\hline
\end{tabular}

A
Mean difference Mean difference

IV, random, $95 \% \mathrm{Cl} \quad$ IV, random, $95 \% \mathrm{CI}$

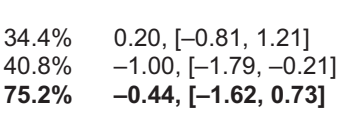

$0.20,[-0.81,1.21]$
$-1.00,[-1.79,-0.21]$
$-\mathbf{0 . 4 4},[-1.62,0.73]$

$-0.44,[-1.62,0.73]$

$34.4 \%$

$75.2 \%$

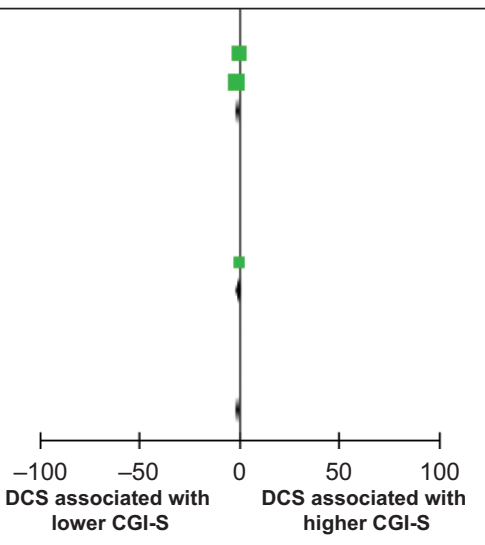

\begin{tabular}{|c|c|c|c|c|c|c|c|c|}
\hline Study or subgroup & $\begin{array}{l}\text { DCS } \\
\text { Mean }\end{array}$ & SD & Total & $\begin{array}{l}\text { Place } \\
\text { Mean }\end{array}$ & bo & Total & Weight & $\begin{array}{l}\text { Mean difference } \\
\text { IV, fixed, } 95 \% \mathrm{CI}\end{array}$ \\
\hline \multicolumn{9}{|c|}{ 3.1.1 DCS taken before each session } \\
\hline Storch $2007^{8}$ & 2.5 & 1.4 & 12 & 2.7 & 1.8 & 12 & $28.8 \%$ & $-0.20,[-1.49,1.09]$ \\
\hline Storch $2010^{19}$ & 2.6 & 1.3 & 15 & 2.1 & 1.4 & 15 & $51.3 \%$ & $0.50,[-0.47,1.47]$ \\
\hline $\begin{array}{l}\text { Subtotal }(95 \% \mathrm{Cl}) \\
\text { Heterogeneity: } \chi^{2}=\end{array}$ & & & $\begin{array}{l}27 \\
0.39\end{array}$ & $p^{2}=0$ & & 27 & $80.2 \%$ & $0.25,[-0.53,1.02]$ \\
\hline
\end{tabular}

Test for overall effect: $Z=0.63(P=0.53)$

3.1.2 DCS taken before each session 5-9

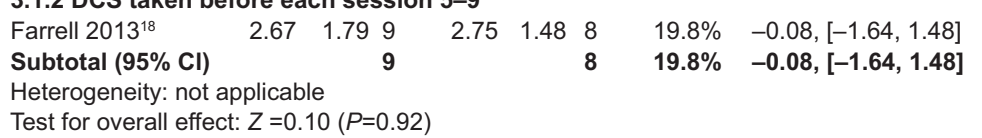

Test for overall effect: $Z=0.10(P=0.92)$

Total $(95 \% \mathrm{Cl}) \quad 36$

Heterogeneity: $\chi^{2}=0.86, d f=2(P=0.65) ; P^{2}=0 \%$

Test for overall effect: $Z=0.52(P=0.60)$

Test for subgroup differences: $\chi^{2}=0.14, d f=1(P=0.71), P^{2}=0 \%$

$35 \quad 100.0 \% \quad 0.18,[-0.51,0.88]$

Mean difference
IV, fixed, $95 \% \mathrm{Cl}$

Figure 5 Forest plots of the effect of DCS versus placebo on CGI-S value or on deceasing CGI-S values of the patients receiving behavioral therapy at posttreatment. Notes: (A) Forest plot of comparison of the effect of DCS and placebo on CGI-S value of the patients receiving behavioral therapy at posttreatment; overall effect for continuous outcome (random-effect model). The diamond stood for pooled effect. No significant difference between the effect of DCS and placebo on CGI-S value of the patients receiving behavioral therapy at posttreatment. (B) Forest plot of comparison of the effect of DCS and placebo on decreasing CGI-S of the patients receiving behavioral therapy at posttreatment; overall effect for continuous outcome (fixed-effect model). The diamond stood for pooled effect. No significant difference between the effect of DCS and placebo on decreasing CGI-S of the patients receiving behavioral therapy at posttreatment.

Abbreviations: DCS, D-cycloserine; Y-BOCS, Yale-Brown Obsessive Compulsive Scale; Cl, confidence interval; SD, standard deviation; CGI-S, Clinical Global Impression Severity Scale; IV, inverse variance; $d f$, degrees of freedom. 
both groups were treatment responders and approximately one-half or more of the patients in both groups achieved clinical remission at posttreatment: $(\mathrm{OR}=0.95 ; 95 \%$ $\mathrm{CI}=[0.29,3.13] ; P=0.94 ; I^{2}=0$ [Figure 6]) and (OR $=0.99 ; 95 \% \mathrm{CI}=[0.39,2.56] ; P=0.99 ; I^{2}=0$ [Figure 7]), respectively. This result indicated that when measured at posttreatment, DCS-augmented ERP therapy did not show an advantage in increasing treatment responders nor in helping OCD patients achieve clinical milestones, such as clinical remission, when compared to placebo-augmented ERP therapy.

\section{Sensitivity analysis, heterogeneity, and publication bias}

Both meta-analyses comparing the efficacy of DCSaugmented therapy and placebo-augmented therapy in increasing the number of treatment responders and in increasing the number of subjects achieving clinical remission at posttreatment were robust to sensitivity analysis, with the overall $P$-value remaining insignificant when each of the included studies was individually removed from the analysis (data not shown).

No heterogeneity was found in either of the meta-analyses (Figures 6 and 7). Further funnel plots used to evaluate publication bias for both analyses were both symmetrical, indicating none or very little publication bias for both metaanalyses (data not shown).

\section{Discussion}

Our meta-analysis did not reveal significant difference between DCS-augmented ERP therapy and placeboaugmented ERP therapy in Y-BOCS value and its decrease at midtreatment, posttreatment, and 3-month follow-up for OCD patients. Further, according to our analysis, compared to placebo control, DCS did not lead to significantly different CGI-S values nor significantly greater decrease in CGI-S values at posttreatment for OCD patients. In addition, no significant difference in proportion of treatment responders and proportions of OCD subjects achieving clinical remission status were associated with DCS versus placebo. However, patients in both DCS and placebo groups showed substantial improvement in their symptomatic severity, such substantial improvement was reflected by the sharp decrease of their Y-BOCS values at midtreatment, post and 3-month follow-up, also by the sharp decrease of their CGI-S values at posttreatment, and finally by the high proportions of treatment responders and of subjects achieving clinical remission status at posttreatment. Further, although not significant, when measured at midtreatment, the DCS-augmented therapy did show a trend toward a lowered/decreased Y-BOCS value compared to placebo-augmented therapy, and this trend was more pronounced in the subpopulation of DCS taken before each of the sessions. Also, when measured at posttreatment, although not significant, in the subpopulation of DCS taken before some of the sessions, the DCS-augmented therapy

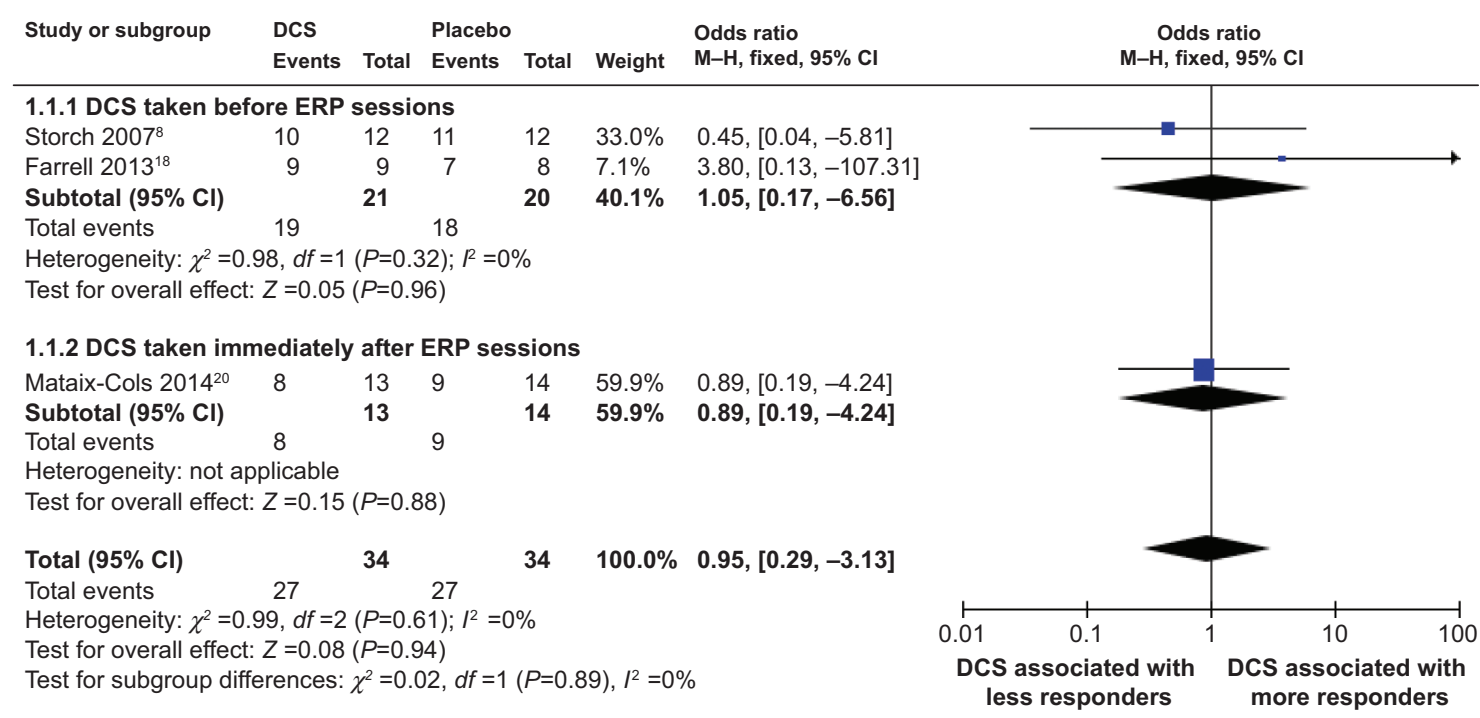

Figure 6 Forest plot of the effect of DCS versus placebo on proportion of responders to behavioral therapy at posttreatment.

Notes: Forest plot of comparison of the effect of DCS and placebo on proportions of responders to behavioral therapy at posttreatment. Overall effect for dichotomous outcome (fixed-effect model). The diamond stood for pooled effect. No significant difference between the effect of DCS and placebo on proportions of responders to behavioral therapy.

Abbreviations: DCS, D-cycloserine; Cl, confidence interval; M-H, Mantel-Haenszel; ERP, exposure and prevention; $d f$, degrees of freedom. 


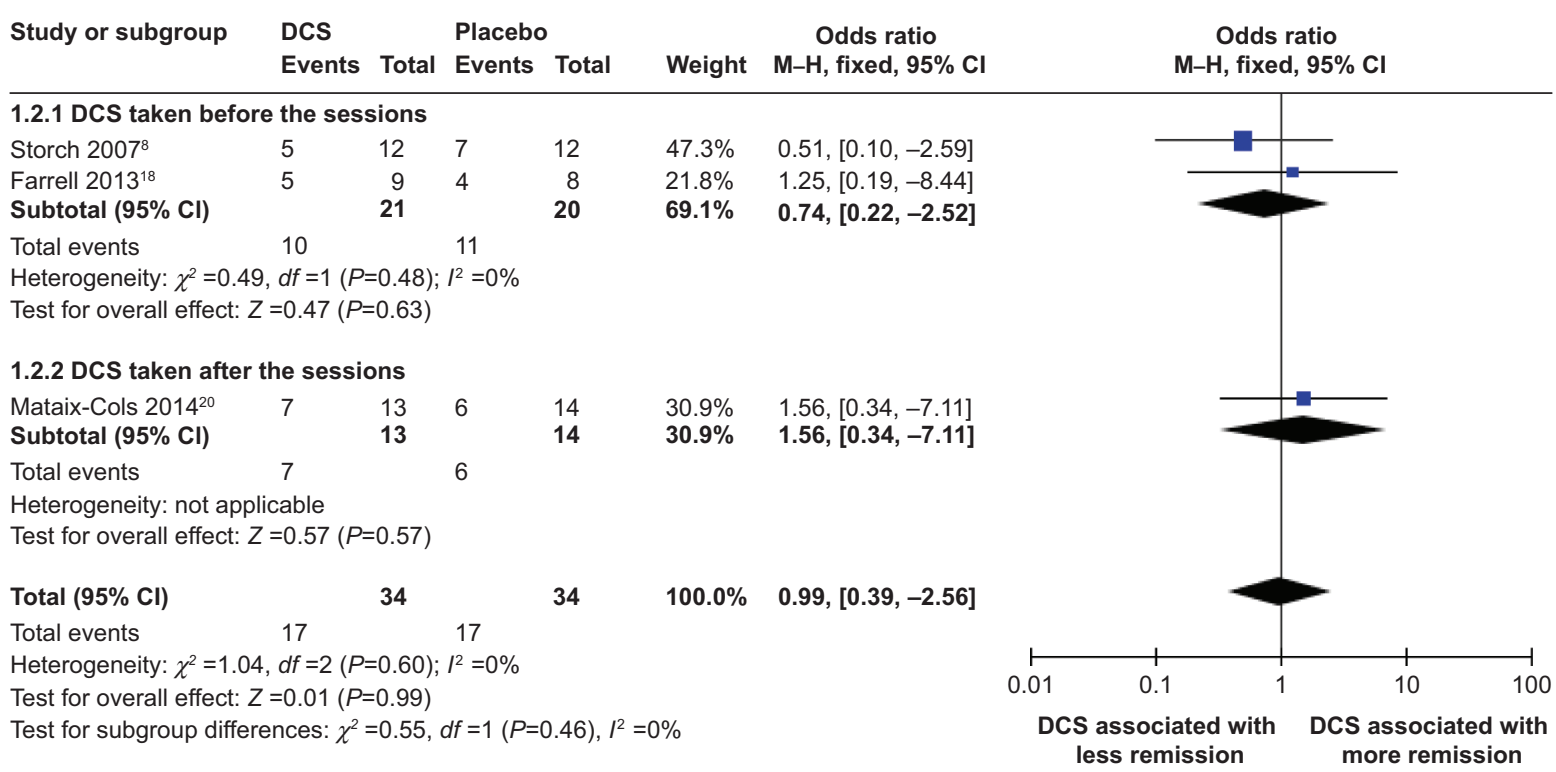

Figure 7 Forest plot of the effect of DCS versus placebo on proportion of behavioral therapy patients meeting remission status criteria at posttreatment.

Notes: Forest plot of comparison of the effect of DCS and placebo on proportions of patients of behavioral therapy meeting remission status criteria at posttreatment. Overall effect for dichotomous outcome (fixed-effect model). The diamond stood for pooled effect. No significant difference between the effect of DCS and on proportions of patients of behavioral therapy meeting remission status criteria at posttreatment.

Abbreviations: DCS, D-cycloserine; Cl, confidence interval; $\mathrm{M}-\mathrm{H}$, Mantel-Haenszel; $d f$, degrees of freedom.

did show a trend toward a significantly lowered/decreased Y-BOCS value compared to placebo-augmented therapy. These results suggested that with careful optimization of DCS-augmented ERP therapy by fine-tuning timing and dosing of DCS administration and number and frequency of ERP sessions, DCS may enhance the efficacy of ERP therapy in reducing the symptomatic severity of OCD patients especially at early stage of the treatment that could possibly last until posttreatment.

The fact that our meta-analysis did not reveal overall significant difference in the efficacies of DCS-augmented therapy in improving OCD symptomatic severity appears somewhat inconsistent with the result of the meta-analysis performed by Bontempo et $\mathrm{al}^{21}$ which showed a significant benefit from the DCS augmentation for the behavioral therapy for anxiety disorders. Their meta-analysis included data from nine studies, four of which were also included in our metaanalysis. ${ }^{8,16,17,19}$ However, their meta-analysis includes studies on all types of anxiety, such as social phobia, panic disorder, and agoraphobia. Their Figure 2 showed that three of the four studies - also included in our analyses ${ }^{8,17,19}$ - did not show significant benefit of the DCS augmentation; therefore, our result did not contradict their meta-analysis result. One possible reason that DCS augmentation works less effectively in OCD subjects than in subjects with other types of anxiety is that the heterogeneity of DCS differs from that of social phobia, agoraphobia, and panic disorder, the clinical manifestations in OCD subjects often vary substantially, and most
OCD patients had more than one obsession and compulsion; their treatments need to target multiple conditioned stimuli, while patients with social phobia, agoraphobia, and panic disorder often are exposed to one conditioned stimulus, and their treatments only need to target one conditioned stimulus. DCS may be more effective in helping specific symptom subtypes, rather than a whole range of subtypes.

Our results showed that when measured at midtreatment, although not significant, DCS-augmented therapy did show a trend toward a lowered/decreased Y-BOCS value compared to the placebo-augmented therapy, and this trend was more pronounced in the subpopulation of DCS taken before each of the sessions. Also, when measured at posttreatment, although not significant, in the subpopulation of DCS taken before some of the sessions, DCS-augmented therapy did show a trend toward a lowered/decreased Y-BOCS value compared to placebo-augmented therapy. This result was consistent with Chasson et $\mathrm{al}^{49}$ who reanalyzed data from Wilhelm et $\mathrm{al}^{16}$ and concluded that the course of ERP augmented with DCS was significantly faster over the ten-session course compared to placebo-augmented ERP, especially in the first one-half of the ERP. They further suggested that the DCS did not amplify the effect of ERP; rather, it made the treatment effect of ERP start sooner. Although DCS may not lose its effect over the repeated use in each ERP session, it could exhaust its maximum utility after it accelerated the effects of ERP. Therefore, they concluded that the DCS could reduce the number of ERP sessions 
needed and, thus, reduce treatment cost, treatment drop, refusal rate, and also help to improve access to the limited number of experienced therapists.

The overall lack of significant difference from the results of our meta-analyses could be caused by multiple factors, some of which could potentially provide some clues on how to optimize DCS augmentation.

First, since patients in both the DCS group and the placebo group showed a sharp decrease in their Y-BOCS value and their CGI-S value consistently throughout the treatment, and a high proportion of patients in both groups responded to treatment and achieved clinical remission status at posttreatment, the ceiling effect may mask the DCS's advantage over the placebo, since it is possible that the effects of DCS may only be obvious when compared to an ineffective treatment, as suggested by Guastella et al. ${ }^{51}$

Second, methodological differences among the included studies may also obscure the effect of DCS. DCS was taken before each of the ERP sessions in three included studies, ${ }^{8,16,17}$ each with different intervals between when the DCS was taken and when the ERP sessions began. It was taken before some of the ERP sessions in two included studies ${ }^{18,19}$ and was taken after each of the sessions in one included study. ${ }^{20}$ The dosage of DCS ranged from 25-250 mg for different studies; the frequency of the ERP sessions also differed for each included study. Also, importantly, for measurement taken at midtreatment, different studies took measurement at different time points of their studies, ranging from after the fourth ERP session to after the sixth ERP session. All of these methodological differences could contribute to inconsistency of the results from the various studies included and lead to the insignificance of the results. For example, Kushner et $\mathrm{al}^{17}$ found decreasing DCS effects after the fourth session related to a potential paradoxical antagonist NMDA effect observed when high and/or chronic DCS doses were used. If this is true, then taking midtreatment measurements after the fifth or sixth session may mask the significance of the DCS effect.

Dosing of DCS may also play a role in masking the true effect of the DCS augmentation, since it was found that DCS may have a narrow therapeutic range when used to enhance learning and that the NMDA receptor could be desensitized after prolonged exposure to DCS. ${ }^{16}$ Therefore, when a high dose of DCS was used as in Storch et $\mathrm{al}^{8}$ such a high dose of DCS might attenuate its own beneficial effect on ERP therapy. This, coupled with the finding mentioned previously by Kushner et $\mathrm{al}^{17}$ regarding the potential paradoxical antagonist NMDA effect, suggested the use of a treatment protocol that uses the lowest possible effective dose of DCS and spaces ERP sessions apart further than semiweekly. ${ }^{17}$

The timing of the DCS administration is also important. It has been reported that DCS might lose its efficacy if given too early before extinction training; however, one of the included studies $^{8}$ in this meta-analysis administered DCS 4 hours before the ERP session, and another one ${ }^{20}$ administered it right after each session. Neither of these two studies found a significant benefit of the DCS augmentation. According to the result of Kushner et al, Wilhelm et al, and Farrell et al ${ }^{16-18}$ DCS was the most effective when administered immediately before (such as 1-2 hours before) the ERP sessions.

Further, several studies have indicated that the augmentation effect of DCS was time-limited; it was most powerful early in the treatment, and over time, the placebo group might catch up. ${ }^{16}$ This could explain the nonsignificant difference between the DCS group and the placebo group when measured at posttreatment and 3-month follow-up, and just as suggested by Chasson et $\mathrm{al}^{49}$ the main benefit of DCS could be the reduction of the number of ERP sessions needed, reduction of treatment cost, treatment drop and refusal rate, and the improvement of access to the limited number of experienced therapists.

There are some limitations in our study. First, the number of available studies was relatively low, and all of them contained a small sample size. This would inevitably lead to a reduced power of detection; more studies with larger sample sizes are needed to further evaluate the benefit of DCS augmentation in the ERP therapy of OCD patients. Second, various included studies used different methodological approach in terms of dosing, timing, and frequency of the DCS administration, number, and frequency of ERP sessions; such a difference would lead to inconsistent results and mask the true effect of DCS augmentation.

On the other hand, our study has its strength. We analyzed the effect of DCS augmentation using multiple outcome measures (Y-BOCS, CGI-S, proportion of treatment responders, and proportion of patients achieving clinical remission) taken at different time points of the treatment (midtreatment, posttreatment, and 3-month follow-up) so as to get a comprehensive understanding of the effect of the DCS augmentation.

\section{Conclusion}

In conclusion, our meta-analysis did not show significant effects of the DCS augmentation in the ERP therapy for the OCD patients - except when measured at midtreatment and compared to the placebo group - DCS augmentation did show 
a tread toward lower/decreased Y-BOCS, which was more pronounced in the subpopulation of DCS taken before each of the sessions. Also, when measured at posttreatment and in the subpopulation of DCS taken before some of the ERP sessions, DCS augmentation showed a trend toward lower/ decreased Y-BOCS. Our results suggested that - with careful optimization of DCS-augmented ERP therapy by fine-tuning the timing and dosing of DCS administration and the number and frequency of ERP sessions - DCS may enhance the efficacy of ERP therapy in reducing the symptomatic severity of OCD patients especially at early stage of the treatment; therefore, DCS augmentation could possibly reduce treatment cost, treatment drop, refusal rate, and also help to improve access to the limited number of experienced therapists.

\section{Disclosure}

The authors report no conflicts of interest in this work.

\section{References}

1. American Psychiatric Association. Diagnostic and Statistical Manual of Mental Disorders. 4th ed. Washington, DC: American Psychiatric Association; 2000.

2. Kessler RC, Berglund P, Demler O, Jin R, Merikangas KR, Walters EE. Lifetime prevalence and age-of-onset distributions of DSM-IV disorders in the National Comorbidity Survey Replication. Arch Gen Psychiatry. 2005;62(6):593-602.

3. Heyman I, Fombonne E, Simmons H, Ford T, Meltzer H, Goodman R. Prevalence of obsessive-compulsive disorder in the British nationwide survey of child mental health. Int Rev Psychiatry. 2003;15(1-2): $178-184$.

4. Jenike MA. Clinical practice. Obsessive-compulsive disorder. $N$ Engl J Med. 2004; 350(3):259-265.

5. Storch EA, Merlo LJ. Obsessive-compulsive disorder: strategies for using CBT and pharmacotherapy. J Fam Pract. 2006;55(4): 329-333.

6. Blier P, Habib R, Flament MF. Pharmacotherapies in the management of obsessive-compulsive disorder. Can J Psychiatry. 2006;51(7): 417-430.

7. Denys D. Pharmacotherapy of obsessive-compulsive disorder and obsessive-compulsive spectrum disorders. Psychiatr Clin North Am. 2006; 29(2):553-584, xi.

8. Storch EA, Merlo LJ, Bengtson M, et al. D-cycloserine does not enhance exposure-response prevention therapy in obsessive-compulsive disorder. Int Clin Psychopharmacol. 2007;22(4):230-237.

9. Davis M. Role of NMDA receptors and MAP kinase in the amygdala in extinction of fear: clinical implications for exposure therapy. Eur $J$ Neurosci. 2002;16(3):395-398.

10. Norberg MM, Krystal JH, Tolin DF. A meta-analysis of D-cycloserine and the facilitation of fear extinction and exposure therapy. Biol Psychiatry. 2008;63(12):1118-1126.

11. Davis M, Ressler K, Rothbaum BO, Richardson R. Effects of D-cycloserine on extinction: translation from preclinical to clinical work. Biol Psychiatry. 2006;60(4):369-375.

12. Ressler KJ, Rothbaum BO, Tannenbaum L, et al. Cognitive enhancers as adjuncts to psychotherapy: use of D-cycloserine in phobic individuals to facilitate extinction of fear. Arch Gen Psychiatry. 2004; 61(11):1136-1144.

13. Hofmann SG, Pollack MH, Otto MW. Augmentation treatment of psychotherapy for anxiety disorders with D-cycloserine. CNS Drug Rev. 2006;12(3-4):208-217.
14. Guastella AJ, Richardson R, Lovibond PF, et al. A randomized controlled trial of D-cycloserine enhancement of exposure therapy for social anxiety disorder. Biol Psychiatry. 2008;63(6): 544-549.

15. Otto MW, Tolin DF, Simon NM, et al. Efficacy of d-cycloserine for enhancing response to cognitive-behavior therapy for panic disorder. Biol Psychiatry. 2010;67(4):365-370.

16. Wilhelm S, Buhlmann U, Tolin DF, et al. Augmentation of behavior therapy with D-cycloserine for obsessive-compulsive disorder. Am J Psychiatry. 2008;165(3):335-341; quiz 409.

17. Kushner MG, Kim SW, Donahue C, et al. D-cycloserine augmented exposure therapy for obsessive-compulsive disorder. Biol Psychiatry. 2007;62(8):835-838.

18. Farrell LJ, Waters AM, Boschen MJ, et al. Difficult-to-treat pediatric obsessive-compulsive disorder: feasibility and preliminary results of a randomized pilot trial of D-cycloserine-augmented behavior therapy. Depress Anxiety. 2013;30(8):723-731.

19. Storch EA, Murphy TK, Goodman WK, et al. A preliminary study of D-cycloserine augmentation of cognitive-behavioral therapy in pediatric obsessive-compulsive disorder. Biol Psychiatry. 2010; 68(11):1073-1076.

20. Mataix-Cols D, Turner C, Monzani B, et al. Cognitive-behavioural therapy with post-session D-cycloserine augmentation for paediatric obsessive-compulsive disorder: pilot randomised controlled trial. $\mathrm{Br} \mathrm{J}$ Psychiatry. 2014;204(1):77-78.

21. Bontempo A, Panza KE, Bloch MH. D-cycloserine augmentation of behavioral therapy for the treatment of anxiety disorders: a metaanalysis. J Clin Psychiatry. 2012;73(4):533-537.

22. Goodman WK, Price LH, Rasmussen SA, et al. The Yale-Brown Obsessive Compulsive Scale. II. Validity. Arch Gen Psychiatry. 1989; 46(11):1012-1016.

23. Storch EA, Shapira NA, Dimoulas E, Geffken GR, Murphy TK, Goodman WK. Yale-Brown Obsessive Compulsive Scale: the dimensional structure revisited. Depress Anxiety. 2005;22(1): $28-35$.

24. Sousa MB, Isolan LR, Oliveira RR, Manfro GG, Cordioli AV. A randomized clinical trial of cognitive-behavioral group therapy and sertraline in the treatment of obsessive-compulsive disorder. $J$ Clin Psychiatry. 2006;67(7):1133-1139.

25. Wells GA, Shea B, O'Connell D, et al. The Newcastle-Ottawa Scale (NOS) for assessing the quality of nonrandomised studies in meta-analysis [webpage on the Internet]. Ottawa, Ontario; Ottawa Health Research Institute; 2004. Available from: http:// www.ohri.ca/programs/clinical_epidemiology/oxford.asp. Accessed December 15, 2013.

26. DerSimonian R, Laird N. Meta-analysis in clinical trials. Control Clin Trials. 1986;7(3):177-188.

27. Higgins J, Thompson S, Deeks J, Altman D. Statistical heterogeneity in systematic reviews of clinical trials: a critical appraisal of guidelines and practice. J Health Serv Res Policy. 2002;7(1):51-61.

28. Navarro-Mateu F, Escámez T, Koenen KC, Alonso J, Sánchez-Meca J. Meta-analyses of the 5-HTTLPR polymorphisms and post-traumatic stress disorder. PLoS One. 2013;8(6):e66227.

29. Rapp A, Dodds A, Walkup JT, Rynn M. Treatment of pediatric anxiety disorders. Ann N Y Acad Sci. 2013;1304(1):52-61.

30. Kariuki-Nyuthe C, Gomez-Mancilla B, Stein DJ. Obsessive compulsive disorder and the glutamatergic system. Curr Opin Psychiatry. 2014; 27(1):32-37.

31. Grados MA, Specht MW, Sung HM, Fortune D. Glutamate drugs and pharmacogenetics of OCD: a pathway-based exploratory approach. Expert Opin Drug Discov. 2013;8(12):1515-1527.

32. McGuire JF, Lewin AB, Geller DA, et al. Advances in the treatment of pediatric obsessive-compulsive d-cycloserine with exposure and response prevention. Neuropsychiatry (London). 2012;2(4).

33. Davis M. NMDA receptors and fear extinction: implications for cognitive behavioral therapy. Dialogues Clin Neurosci. 2011;13(4): $463-474$. 
34. Vloet TD, Simons M, Herpertz-Dahlmann B. [Psychotherapeutic and pharmacological treatment of pediatric obsessive-compulsive disorder]. Z Kinder Jugendpsychiatr Psychother. 2012;40(1):29-39; quiz 39. German.

35. Walsh KH, McDougle CJ. Psychotherapy and medication management strategies for obsessive-compulsive disorder. Neuropsychiatr Dis Treat. 2011;7:485-494.

36. Choi DC, Rothbaum BO, Gerardi M, Ressler KJ. Pharmacological enhancement of behavioral therapy: focus on posttraumatic stress disorder. Curr Top Behav Neurosci. 2010;2:279-299.

37. Ganasen KA, Ipser JC, Stein DJ. Augmentation of cognitive behavioral therapy with pharmacotherapy. Psychiatr Clin North Am. 2010; 33(3):687-699.

38. Singer HS, Morris C, Grados M. Glutamatergic modulatory therapy for Tourette syndrome. Med Hypotheses. 2010;74(5):862-867.

39. Abramowitz JS, Taylor S, McKay D. Obsessive-compulsive disorder. Lancet. 2009;374(9688):491-499.

40. Storch EA, Mariaskin A, Murphy TK. Psychotherapy for obsessivecompulsive disorder. Curr Psychiatry Rep. 2009;11(4):296-301.

41. Figee M, Denys D. New pharmacotherapeutic approaches to obsessivecompulsive disorder. CNS Spectr. 2009;14(2 Suppl 3):13-23.

42. Tryon WW, McKay D. Memory modification as an outcome variable in anxiety disorder treatment. J Anxiety Disord. 2009;23(4):546-556.

43. Amaral OB, Roesler R. Targeting the NMDA receptor for fear-related disorders. Recent Pat CNS Drug Discov. 2008;3(3):166-178.

44. Rothbaum BO. Critical parameters for D-cycloserine enhancement of cognitive-behaviorial therapy for obsessive-compulsive disorder. Am J Psychiatry. 2008;165(3):293-296.

45. Hofmann SG. Enhancing exposure-based therapy from a translational research perspective. Behav Res Ther. 2007;45(9):1987-2001.

46. Siegmund A, Golfels F, Finck C, et al. D-cycloserine does not improve but might slightly speed up the outcome of in-vivo exposure therapy in patients with severe agoraphobia and panic disorder in a randomized double blind clinical trial. J Psychiatr Res. 2011;45(8):1042-1047.

47. Onur OA, Schlaepfer TE, Kukolja J, et al. The N-methyl-D-aspartate receptor co-agonist D-cycloserine facilitates declarative learning and hippocampal activity in humans. Biol Psychiatry. 2010; 67(12):1205-1211.
48. Albelda N, Bar-On N, Joel D. The role of NMDA receptors in the signal attenuation rat model of obsessive-compulsive disorder. Psychopharmacology (Berl). 2010;210(1):13-24.

49. Chasson GS, Buhlmann U, Tolin DF, et al. Need for speed: evaluating slopes of OCD recovery in behavior therapy enhanced with d-cycloserine. Behav Res Ther. 2010;48(7):675-679.

50. Shim SS, Hammonds MD, Vrabel MM. D-cycloserine augmentation for behavioral therapy. Am J Psychiatry. 2008;165(8):1050.

51. Guastella AJ, Lovibond PF, Dadds MR, Mitchell P, Richardson R. A randomized controlled trial of the effect of D-cycloserine on extinction and fear conditioning in humans. Behav Res Ther. 2007;45(4):663-672.

52. First MB, Spitzer R, Gibbon M, Williams J. Structural Clinical Interview for Axis-I DSM-IV Disorders, Patient Edition (SCID-I/P Version 2.0). NewYork: Biometrics Research Department, New York State Psychiatric Institute. 1989.

53. Goodman WK, Price LH, Rasmussen SA, et al. The Yale-Brown Obsessive-Compulsive Scale. I. Development, use, and reliability. Arch Gen Psychiatry. 1989;46(11):1006 -1011.

54. Brown TA, Di Nardo PA, Barlow DH. Anxiety Disorders Interview Schedule for DSM-IV. Albany, New York: University of Albany. 1989.

55. Silverman WK, Albano AM. Anxiety Disorders Interview Schedule for DSM-IV-Child and Parent Versions. San Antonio, TX: Graywind Publications; 1996.

56. Scahill L, Riddle MA, McSwiggin-Hardin M, et al. Children's YaleBrown Obsessive Compulsive Scale: reliability and validity. J Am Acad Child Adolesc Psychiatry. 1997;36(6):844-852.

57. Guy W. ECDEU Assessment Manual for Psychopharmacology, revised. Washington, DC: US Government Printing Office; 1976. Available from: https://ia600503.us.archive.org/10/items/ecdeuassessmentm1933guyw/ ecdeuassessmentm1933guyw.pdf. Accessed December 15, 2013.
Drug Design, Development and Therapy

\section{Publish your work in this journal}

Drug Design, Development and Therapy is an international, peerreviewed open-access journal that spans the spectrum of drug design and development through to clinical applications. Clinical outcomes, patient safety, and programs for the development and effective, safe, and sustained use of medicines are a feature of the journal, which

\section{Dovepress}

has also been accepted for indexing on PubMed Central. The manuscript management system is completely online and includes a very quick and fair peer-review system, which is all easy to use. Visit http://www.dovepress.com/testimonials.php to read real quotes from published authors.

Submit your manuscript here: http://www.dovepress.com/drug-design-development-and-therapy-journal 